\title{
Entrainment, Mixing, and Microphysics in Trade-Wind Cumulus
}

\author{
Hermann E. GERBER, Glendon M. FRICK \\ Gerber Scientific Inc., Reston, Virginia, USA \\ Jorgen B. JENSEN \\ National Center for Atmospheric Research, Boulder, Colorado, USA \\ and \\ James G. HUDSON \\ Desert Research Institute, Reno, Nevada, USA \\ (Manuscript received 7 December 2007, in final form 31 March 2008)
}

\begin{abstract}
The vertical evolution of microphysics in trade-wind cumuli $(\mathrm{Cu})$ observed from the NCAR C-130 research aircraft during one flight of the RICO (Rain in Cumulus Over the Ocean) study is analyzed. Conditional sampling of $>200 \mathrm{Cu}$ traversed on this flight is used to chose $\mathrm{Cu}$ for which the aircraft penetrated single and growing $\mathrm{Cu}$ turrets about 250-m below cloud top where maximum LWC is often found and where radar has often observed initial stages of precipitation. The vertical evolution of the sampled set of $\mathrm{Cu}$ was assumed to follow Lagrangian behavior. The entrainment rate, entrained parcel scales, mixing mechanisms, and effects on the droplet size distribution are measured and evaluated. A parcel model is applied over the $1100-\mathrm{m}$ maximum $\mathrm{Cu}$ height of the traverses to determine the relationship between the observed large number of small droplets and the fewer ultra-giant sea-salt nuclei (UGN) in order to assess the role of these nuclei in evolving the size spectrum and in causing a growing "drizzle tail". New insight on these topics is obtained by using the PVM (Particle Volume Monitor) probe to measure incloud microphysics with $10-\mathrm{cm}$ resolution.

The results include the following: Entrainment causes primarily dilution of the drops without significant size changes, thus either extreme inhomogeneous mixing or more likely homogeneous mixing resulting from mixing with cool and humid entrained air take place. The entrained parcels are surprisingly small following lognormal behavior and decaying rapidly upon entering the $\mathrm{Cu}$, as a result super-adiabatic drops are not evident. The entrained parcels are consistent with the Bragg-scattering "mantle echo" often observed by radar in small $\mathrm{Cu}$. The FSSP (Forward Scattering Spectrometer Probe) droplet spectra are nearly constant with height. These "self-preserving" spectra are a result of an approximate balance between dilution by entrainment of droplets originating at cloud base, droplet activation on entrained CCN (cloud condensation nuclei), and detrainment and coalescence losses. Sea-salt nuclei follow Woodcock's wind dependence, and are shown with the parcel model to play an important role in forming the observed drizzle that increases with cloud height. Accretion is the dominant coalescence mechanism near cloud top in these $\mathrm{Cu}$.
\end{abstract}

Corresponding author: Hermann E. Gerber, Gerber Scientific Inc., 1643 Bentana Way, Reston, VA 20190, USA.

E-mail: hgerber6@comcast.net

(C)2008, Meteorological Society of Japan 


\section{Introduction}

This observational study investigates the vertical evolution of the microphysics of small, warm, trade-wind cumuli $(\mathrm{Cu})$ probed by the NCAR C-130 research aircraft during the 2004-2005 RICO (Rain in Cumulus Over the Ocean; Rauber et al. 2007) field campaign in the Carribean. Earlier studies on small, warm cumuli span more than 50 years resulting in a voluminous literature. A few of the earliest citations include Stommel (1947), Malkus (1949), Warner (1955), and Squires (1958). More recent work is based on extensive aircraft field campaigns such as BOMEX (Barbados Oceanographic and Meteorological Experiment), CCOPE (Cooperative Convective Precipitation Experiment), JHWRP (Joint Hawaii Warm Rain Project), and SCMS (Small Cumulus Microphysics Study), all dealing with small $\mathrm{Cu}$. A short list of publications resulting from that work includes Jensen et al. (1985), Raga et al. (1990), Blyth and Latham (1990), Siebesma and Cuijpers (1995), Kreuger et al. (1997), Knight and Miller (1998), Su et al. (1998), Blyth et al. (2003), Lasher-Trapp et al. (2005), and Stevens and Seifert (2007). The cloud phenomena dealt with in the earlier work include the warm-rain process, the effect of CCN (cloud condensation nuclei) and ultra-giant nuclei (UGN) on droplet spectra evolution, the entrainment and detrainment process, the homogeneous vs inhomogeneous mixing processes following entrainment, and their interrelationships. A full understanding of these phenomena has yet to be achieved. This study further investigates in turn each of these topics for some RICO Cu.

RICO data from the C-130 is analyzed in a manner not previously done for the earlier aircraft field campaigns. While the earlier campaigns on small, warm $\mathrm{Cu}$ also traversed with aircraft $\mathrm{Cu}$ at different levels to estimate their in-situ vertical variability, our conditionally-sampled traverses are limited to those where the aircraft passes through the buoyant "bubble" near the top of the rising $\mathrm{Cu}$ turrets. This was done for one RICO flight (RF12), and resulted in a reduced number of traverses from the total of $\sim 200 \mathrm{Cu}$ traverses made for this flight. Given that the aircraft flew predominantly at 5 levels above the LCL (lifting condensation level) provided some traverses through the "bubble" at each level and permitted estimating vertical evolution of this part of the $\mathrm{Cu}$ under the assumption that this procedure mimicked Lagrangian evolu- tion.

The reasons for using this approach relate to the "bubble and wake" conceptual idea of the small $\mathrm{Cu}$ described by Scorer and Ludlam (1953) and in a similar manner by Blyth et al. (1988) and Blyth (1993) where entrainment/detrainment occurs primarily near the top of the growing $\mathrm{Cu}$ turret, and relate to the radar observations during $\mathrm{CaPE}$ (Convection and Precipitation/Electrification Experiment) and SCMS described in Knight and Miller (1998) and Blyth et al. (2003) in which the first radar echo and subsequent precipitation were often observed near the top of actively growing small $\mathrm{Cu}$. This suggests that the present approach should be relevant to the entrainment process and to precipitation initiation, a principal issue of RICO.

This study resembles most the study done by Raga et al. (1990) on small, buoyant $\mathrm{Cu}$ embedded in convective bands upwind of Hawaii (JHWRP study). We differ in that they compiled a data set of traverses by passing through $\mathrm{Cu}$ at various levels over a 20 -min period. We also differ in that we had the ability to look at incloud structure with a resolution of about 2 orders of magnitude finer by using high-rate microphysical data (1000 $\mathrm{hz}, \sim 10-\mathrm{cm}$ in-cloud resolution) for two integrated droplet properties LWC (liquid water content) and mean droplet size $\left(r_{e}\right.$, effective radius) measured by the PVM probe (Gerber et al. 1994). Similarities include using the FSSP (model S-100) and 2D-C large-droplet probe for measuring droplet spectra, and other probes for measuring meteorological and aircraft parameters. (The droplet diameter size range measured by the PVM is approximately 3 $\mu \mathrm{m}-45 \mu \mathrm{m}$, by the FSSP the range is $1.4 \mu \mathrm{m}-44.2$ $\mu \mathrm{m}$, and by the 2D-C the range is $34 \mu \mathrm{m}-1592 \mu \mathrm{m}$. The FSSP has 29 size bins each $1.5-\mu \mathrm{m}$ in diameter, and the 2D-C has 62 size bins each $25-\mu \mathrm{m}$ in diameter.)

The following sections begin with a description of the conditionally-sampled $\mathrm{Cu}$ traverses on flight RF12, including the method used for sampling, and the measured general physical characteristics, microphysics, and thermodynamics. Next the high-rate data is analyzed to gain new insights on the mixing process following entrainment including the role of $\mathrm{CCN}$. The next section deals with the scales of the entrained parcels and relates the scales to the response times of droplet growth and kinetic-energy dissipation. Next, the vertical evolution of the droplet spectrum is shown and estimated with a parcel model including coalescence 
in an attempt to explain the drizzle drops appearing near the top of the deepest $\mathrm{Cu}$. A final section gives conclusions.

\section{Conditionally-sampled cumuli}

Flight RF12 (Jan. 11, 2005; long. $-62^{\circ} \mathrm{E}$, lat. $\sim 18^{\circ} \mathrm{N}$ ) was chosen for conditional sampling since the $\mathrm{Cu}$ had somewhat larger droplet and smaller drizzle concentrations than other RICO flights. This permitted the vertical evolution of the microphysics to be studied without a significant depletion of LWC by precipitation. The vertical distribution of traverses through the $\sim 200$ cumuli on flight RF12 is illustrated in Fig. 1 where all 1-hz $(\sim 100-\mathrm{m}$ resolution) LWC data collected by the PVM and 2D-C probes are shown. As illustrated the traverses were flown predominantly at 7 levels. The passes just above cloud base are not dealt with in the subsequent analysis, and the two closely-spaced passes about $800-\mathrm{m}$ above the surface are combined to represent one level. Also shown in Fig. 1 for each of the remaining 5 levels are the largest values of LWC from the $\sim 10-\mathrm{cm}$ resolution PVM data. These high resolution LWC values are $\sim 25 \%$ larger than the largest $100-\mathrm{m}$ resolution $\mathrm{LWC}$ values. The large

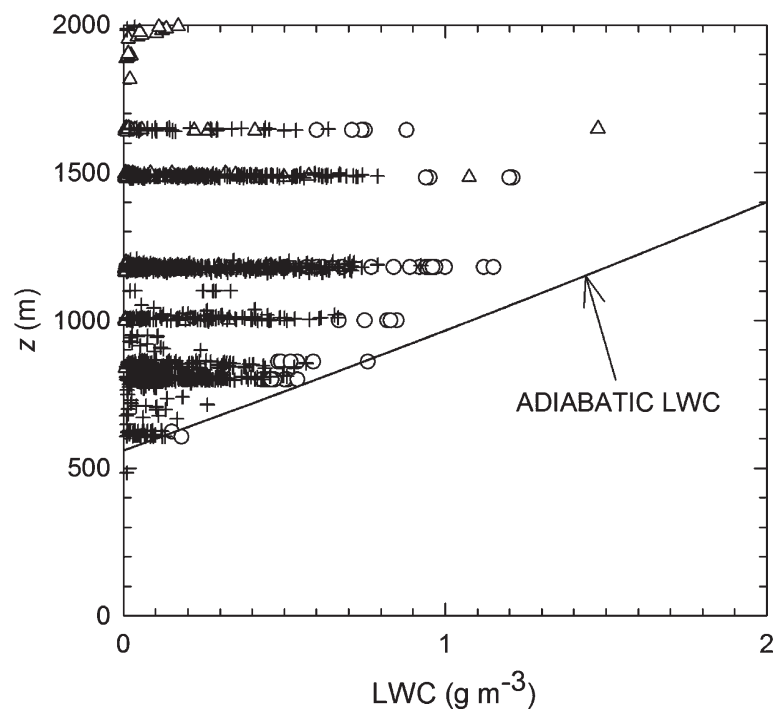

Fig. 1. Liquid water content LWC as a function of height $z$ in RICO trade-wind $\mathrm{Cu}$ on $\mathrm{C}-130$ flight RF12. Crosses are 1-hz PVM data, circles are 1000-hz PVM data, and triangles are 1-hz 2D-C data. The curve indicates the expected adiabatic LWC profile given cloud-base temperature and pressure. differences between the measured LWC values and the calculated adiabatic LWC curve show that there is pervasive entrainment into the $\mathrm{Cu}$ on this flight.

A forward-looking digital video was a new feature on the C-130 aircraft for RICO. This permitted practical viewing of the $\mathrm{Cu}$, as well as enabling quantitative estimates to be made of $\mathrm{Cu}$ geometry. Viewing the video for RF12 leaves the impression that these $\mathrm{Cu}$ reflect a substantial complexity, with the ideal "bubble and wake" geometry hardly ever observed. Some $\mathrm{Cu}$ are vigorous, others are not, others are dissipating, and others form complex clusters. Given this complexity, it was decided not to analyze all $\sim 200 \mathrm{Cu}$, but to follow in the footsteps of Raga et al. (1990) and analyze only those that met a similar sampling criterion. In their study of the Hawaiian rain-band $\mathrm{Cu}$ they chose $\mathrm{Cu}$ with vigorous updrafts. Here we do the same with some additional constrains: 1) the vertical velocity is positive in at least $80 \%$ of the $\mathrm{Cu}$ traverse (for the bottom 4 flight levels), 2) the top of the $\mathrm{Cu}$ is visible in the video so that the distance between cloud penetration and cloud top can be estimated, 3) the $\mathrm{Cu}$ is traversed below but near cloud top ( 200-m the desired distance), and 4) the $\mathrm{Cu}$ consisting of individual turrets are chosen.

The method for relating distances on the video display screen to cloud distances requires reference to some known distance on the video. This is done by measuring the distance on the screen when cloud base is visible for well defined $\mathrm{Cu}$, and when the aircraft is at a known distance from the $\mathrm{Cu}$ given by aircraft speed times the elapsed time $\Delta t(s)$ before intercepting the $\mathrm{Cu}$. Given the known height of the LCL (equivalent to cloud-base height $z_{0}$ ) and the altimeter reading leads to the known distance between the LCL and the point of aircraft penetration, and to an approximately linear relationship given by

$$
\Delta t \approx 0.11 \frac{\Delta z}{\Delta z_{s}}-2.98
$$

where $\Delta z(\mathrm{~m})$ is the cloud dimension, and $\Delta z_{s}$ $(\mathrm{cm})$ is the corresponding dimension on the video screen. Equation (1) can be applied to any other screen by replacing $\Delta z_{s}$ with $\Delta z_{s}[5.40(\mathrm{~cm}) / X(\mathrm{~cm})]$ where $X(\mathrm{~cm})$ is the width of the large runway arrowhead in the first video image for RF12.

The cloud top height $z_{t}$ was obtained using Eq. (1) and is shown in Fig. 2 where each of the 47 


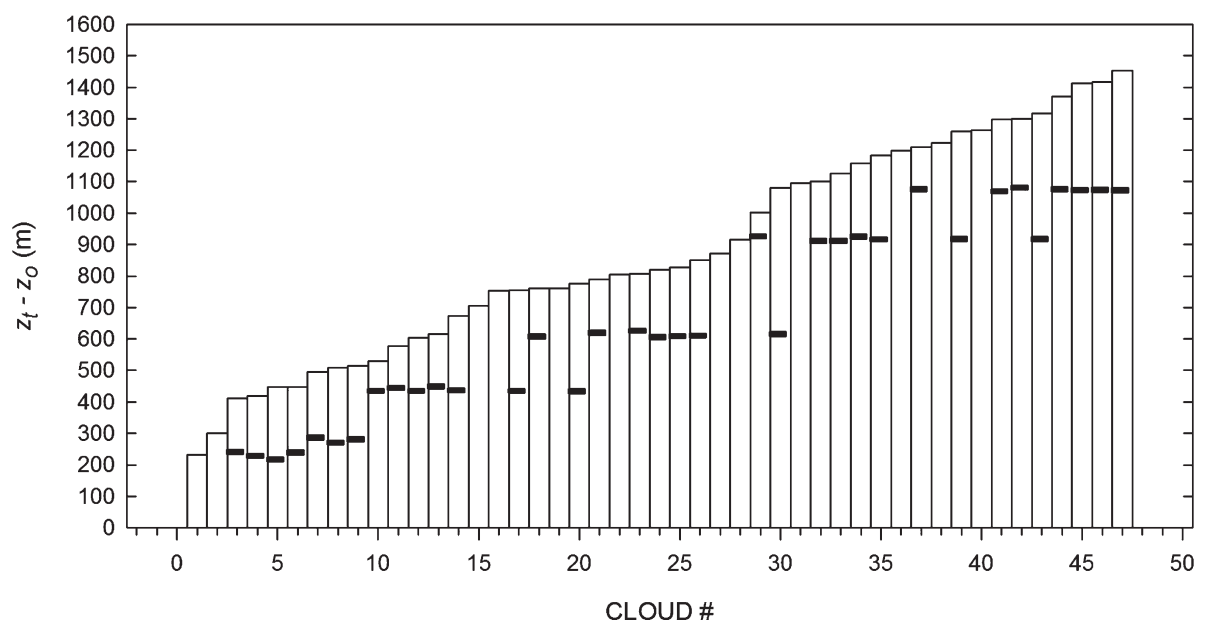

Fig. 2. Height $z_{t}$ of cloud top measured from cloud base $z_{0}$ for 47 individual trade-wind $\mathrm{Cu}$ on flight RF12. Dark horizontal bars indicate the $35 \mathrm{Cu}$ chosen by conditional sampling for this study (see text), and indicate the penetration height of the aircraft flown at an average distance of about $250-\mathrm{m}$ below cloud top at 5 levels.

Table 1. Time intervals (UTC; hr:min:s) found in the NCAR/RAF data archive for RICO flight RF12 for the penetrations through $\mathrm{Cu}$ depicted in Fig. 2.

\begin{tabular}{cccc}
\hline $\mathrm{Cu} \#$ & Time & $\mathrm{Cu} \#$ & Time \\
\hline 1 & $17: 12: 10-17: 12: 12$ & 25 & $19: 21: 07-19: 21: 12$ \\
2 & $19: 58: 12-19: 58: 17$ & 26 & $17: 33: 57-17: 34: 03$ \\
3 & $16: 48: 25-16: 48: 30$ & 27 & $19: 02: 58-19: 03: 05$ \\
4 & $17: 02: 16-17: 02: 19$ & 28 & $17: 59: 56-17: 59: 57$ \\
5 & $16: 43: 58-16: 44: 04$ & 29 & $18: 13: 29-18: 13: 34$ \\
6 & $17: 03: 42-17: 03: 47$ & 30 & $19: 37: 57-19: 38: 09$ \\
7 & $19: 41: 56-19: 42: 01$ & 31 & $19: 12: 13-19: 12: 21$ \\
8 & $17: 17: 43-17: 17: 49$ & 32 & $18: 11: 18-18: 11: 26$ \\
9 & $19: 51: 27-19: 51: 34$ & 33 & $18: 03: 25-18: 03: 30$ \\
10 & $19: 03: 13-19: 03: 18$ & 34 & $17: 59: 28-17: 59: 45$ \\
11 & $18: 59: 08-18: 59: 12$ & 35 & $17: 56: 34-17: 56: 45$ \\
12 & $18: 54: 05-18: 54: 12$ & 36 & $18: 26: 05-18: 26: 09$ \\
13 & $19: 41: 17-19: 41: 20$ & 37 & $18: 29: 56-18: 30: 02$ \\
14 & $18: 51: 08-18: 51: 13$ & 38 & $17: 41: 24-17: 41: 30$ \\
15 & $17: 33: 51-17: 33: 53$ & 39 & $18: 14: 41-18: 14: 55$ \\
16 & $17: 16: 59-17: 17: 15$ & 40 & $17: 05: 04-17: 05: 19$ \\
17 & $19: 00: 30-19: 00: 36$ & 41 & $18: 27: 09-18: 27: 13$ \\
18 & $17: 22: 19-17: 22: 32$ & 42 & $18: 23: 14-18: 23: 22$ \\
19 & $16: 57: 08-16: 57: 17$ & 43 & $18: 04: 47-18: 04: 53$ \\
20 & $19: 01: 56-19: 02: 02$ & 44 & $18: 25: 10-18: 25: 26$ \\
21 & $17: 35: 25-17: 35: 31$ & 45 & $18: 32: 45-18: 32: 53$ \\
22 & $17: 42: 07-17: 42: 11$ & 46 & $18: 25: 17-18: 25: 25$ \\
23 & $19: 32: 24-19: 32: 30$ & 47 & $18: 29: 17-18: 29: 22$ \\
24 & $17: 49: 26-17: 49: 35$ & & \\
\hline
\end{tabular}

vertical bars represents one $\mathrm{Cu}$, and the short horizontal bars give the heights above cloud base where the aircraft entered the clouds chosen by conditional sampling. The time period over which each $\mathrm{Cu}$ appears in the data archive is listed in Table 1. The accuracy of the dimensions shown in Fig. 2 is estimated as $+/-50 \mathrm{~m}$. Not all the cloud penetrations in Fig. 2 have a horizontal bar, because they did not meet all four criteria listed above as a result of the aircraft skimming too close to cloud top, too deep in the cloud, or encountering fragmented cloud. The remaining $35 \mathrm{Cu}, 7$ at each of 5 levels, form the basis of the following analysis.

Dimensions and some other properties of the set of $35 \mathrm{Cu}$ are listed in Table 2. The mean of the properties of the $7 \mathrm{Cu}$ at each level is given. The average width $W_{d}$ of all $35 \mathrm{Cu}$ is $~ 550 \mathrm{~m}$. This width is similar to the width of the BOMEX trade-wind cumuli, but is much smaller $(\sim 1 / 5$ the size) than the width of the $\mathrm{Cu}$ penetrated in the other major small-Cu field studies (CCOPE, JHWRP, CaPE, SCMS). The penetration length $L_{a}$ is smaller than $W_{d}$ since the aircraft did not always penetrate the $35 \mathrm{Cu}$ near the middle of each cloud. The vertical wind shear averages $2 \mathrm{~m} \mathrm{~s}^{-1} \mathrm{~km}^{-1}$ and is maximum near cloud top.

The microphysics of the $\mathrm{Cu}$ in the five layers is summarized in Table 3 , where numerical values are given for the measured LWC and the mean volume radius $r_{v}$. The latter values are shown in Fig. 3 
Table 2. General characteristics of the seven $\mathrm{Cu}$ at five different levels shown in Fig. 2, with mean values of cloud top $z_{t}$, cloud top minus aircraft level $z_{a}$, aircraft level minus $z_{o}=\mathrm{LCL} \sim 570 \mathrm{~m}$, width of the turret $W_{d}$, length $L_{a}$ of the aircraft pass through the turret, vertical velocity $w$, maximum vertical velocity $w_{\max }$ ( $w$ based on 4-m resolution data), bulk TKE dissipation rate $\varepsilon$, and fractional entrainment $\delta . s(\mathrm{xxx})$ indicates the mean of the sample standard deviation $\mathrm{s}$ for all cloud passes at the given level, and $s[\mathrm{xxx}]$ indicates $\mathrm{s}$ for the mean of the parameter $\mathrm{xxx}$ at the given level; the same convention is used in subsequent tables.

\begin{tabular}{crcccccccccccr}
\hline Level & $\begin{array}{c}z_{a}-z_{o} \\
(\mathrm{~m})\end{array}$ & $\begin{array}{c}z_{t} \\
(\mathrm{~m})\end{array}$ & $\begin{array}{c}z_{t}-z_{a} \\
(\mathrm{~m})\end{array}$ & $\begin{array}{c}W \\
(\mathrm{~m})\end{array}$ & $\begin{array}{c}\mathrm{s}[W] \\
(\mathrm{m})\end{array}$ & $\begin{array}{c}L_{a} \\
(\mathrm{~m})\end{array}$ & $\begin{array}{c}w \\
(\mathrm{~m} / \mathrm{s})\end{array}$ & $\begin{array}{c}\mathrm{s}(w) \\
(\mathrm{m} / \mathrm{s})\end{array}$ & $\begin{array}{c}w_{\max } \\
(\mathrm{m} / \mathrm{s})\end{array}$ & $\begin{array}{c}\varepsilon \\
\left(\mathrm{cm}^{2} / \mathrm{s}^{3}\right)\end{array}$ & $\begin{array}{c}\mathrm{s}[\varepsilon] \\
\left(\mathrm{cm}^{2} / \mathrm{s}^{3}\right)\end{array}$ & $\begin{array}{c}\delta \\
(1 / \mathrm{m})\end{array}$ & $\begin{array}{c}\mathrm{s}[\delta] \\
(1 / \mathrm{m})\end{array}$ \\
\hline 1 & 252 & 1009 & 187 & 544 & 162 & 331 & 1.18 & .791 & 2.40 & 14.01 & 6.75 & $2.29 \mathrm{e}-3$ & $1.28 \mathrm{e}-3$ \\
2 & 439 & 1205 & 196 & 484 & 261 & 266 & 1.25 & 1.13 & 3.01 & 41.34 & 16.26 & $1.26 \mathrm{e}-3$ & $.54 \mathrm{e}-3$ \\
3 & 615 & 1398 & 213 & 453 & 168 & 402 & 1.92 & 1.58 & 4.28 & 63.24 & 46.76 & $.73 \mathrm{e}-3$ & $.23 \mathrm{e}-3$ \\
4 & 918 & 1722 & 234 & 612 & 185 & 454 & 1.90 & 1.67 & 4.88 & 74.61 & 42.37 & $.91 \mathrm{e}-3$ & $.13 \mathrm{e}-3$ \\
5 & 1074 & 1920 & 276 & 631 & 187 & 407 & -.283 & .869 & 1.29 & 29.00 & 32.90 & $6.12 \mathrm{e}-3$ & - \\
\hline
\end{tabular}

Table 3. Microphysics of the seven $\mathrm{Cu}$ at five different levels shown in Fig. 2, with mean values of LWC (liquid water content) and its sample standard deviation for three horizontal data resolutions, total droplet concentration $N$, and mean volume radius $r_{v}$. The latter two parameters correspond to 10-m resolution data. The subscript a indicates expected adiabatic values.

\begin{tabular}{ccccccccccc}
\hline Level & $\begin{array}{c}L W C_{a} \\
\left(\mathrm{~g} / \mathrm{m}^{3}\right)\end{array}$ & $\begin{array}{c}L W C \\
\left(\mathrm{~g} / \mathrm{m}^{3}\right)\end{array}$ & $\begin{array}{c}\mathrm{s}(10 \mathrm{~cm}) \\
\left(\mathrm{g} / \mathrm{m}^{3}\right)\end{array}$ & $\begin{array}{c}\mathrm{s}(50 \mathrm{~cm}) \\
\left(\mathrm{g} / \mathrm{m}^{3}\right)\end{array}$ & $\begin{array}{c}\mathrm{s}(1000 \mathrm{~cm}) \\
\left(\mathrm{g} / \mathrm{m}^{3}\right)\end{array}$ & $\begin{array}{c}N \\
(\mathrm{No} / \mathrm{cc})\end{array}$ & $\begin{array}{c}\mathrm{s}[N] \\
(\mathrm{No} / \mathrm{cc})\end{array}$ & $\begin{array}{c}r_{v a} \\
(\mu \mathrm{m})\end{array}$ & $\begin{array}{c}r_{v} \\
(\mu \mathrm{m})\end{array}$ & $\begin{array}{c}\mathrm{s}\left(r_{v}\right) \\
(\mu \mathrm{m})\end{array}$ \\
\hline 1 & .605 & .284 & .084 & .078 & .063 & 95 & 12 & 11.4 & 9.2 & 2.0 \\
2 & 1.00 & .427 & .142 & .136 & .128 & 97 & 22 & 13.5 & 10.6 & 3.1 \\
3 & 1.42 & .520 & .160 & .153 & .145 & 112 & 25 & 15.2 & 10.2 & 1.7 \\
4 & 2.11 & .536 & .196 & .184 & .173 & 116 & 11 & 17.3 & 10.6 & 2.4 \\
5 & 2.46 & .331 & .142 & .135 & .125 & 54 & 35 & 18.2 & 11.9 & 3.7 \\
\hline
\end{tabular}

as a function of height $\left(z_{a}-z_{0}\right)$ above the LCL along with the expected adiabatic profile of $r_{v}$ calculated by combining adiabatic LWC with measured droplet concentrations (see Eq. (9) in the next section). The measured values of $r_{v}$ are nearly independent of height above the first level, and clearly illustrate the degree of sub-adiabatic behavior. Also shown in Table 3 and plotted in Fig. 4 are mean values of the measured droplet concentration $N$ for each level. In addition Fig. 4 shows the vertical profile of $\mathrm{CCN}$ concentrations for a critical supersaturation of $1.5 \%$ as measured during RF12 on the C-130 (Hudson 1989; Hudson and Mishra 2007). Both concentrations are approximately constant with height including below and above the $\mathrm{Cu}$, suggesting that this layer is well mixed with respect to aerosol. The approximate constant $N$ with height appears to be typical for small Cu (Blyth and Latham 1990; Raga et al. 1990; Hudson and Yum 2001).

Table 4 gives mean values of pressure, temperature, and mixing ratios at the 5 levels. The table also shows that the incloud ambient buoyancy difference $\Delta \theta_{v}$ was on the average slightly negative. The latter is unrealistic given that the vertical velocity $w$ (Table 2) and the droplet concentration $N$ (Table 3) increase somewhat with height. The C-130 incloud temperature measurements with the Rosemount and OPHIR probes were of inadequate accuracy with the former suffering wetting and the latter responding over too long of a distance. The incloud temperatures were estimated using the Lyman-Alpha vapor mixing ratio data and applying the Clausius-Clapeyron relationship.

Listed in Table 2 and shown in Fig. 5 is the mean turbulent kinetic energy dissipation rate $\varepsilon$ for the $\mathrm{Cu}$ calculated at each level using

$$
\varepsilon=V^{\prime 3} L_{p}{ }^{-1},
$$

where $V^{\prime}$ is the root mean square gust velocity measured by the gust probe on the C-130 nose, and $L_{p}$ is the "penetration depth" (Tennekes and Driedonks 1981) given a value of $40 \mathrm{~m}$.

Figure 6 and Table 2 show the fractional entrain- 


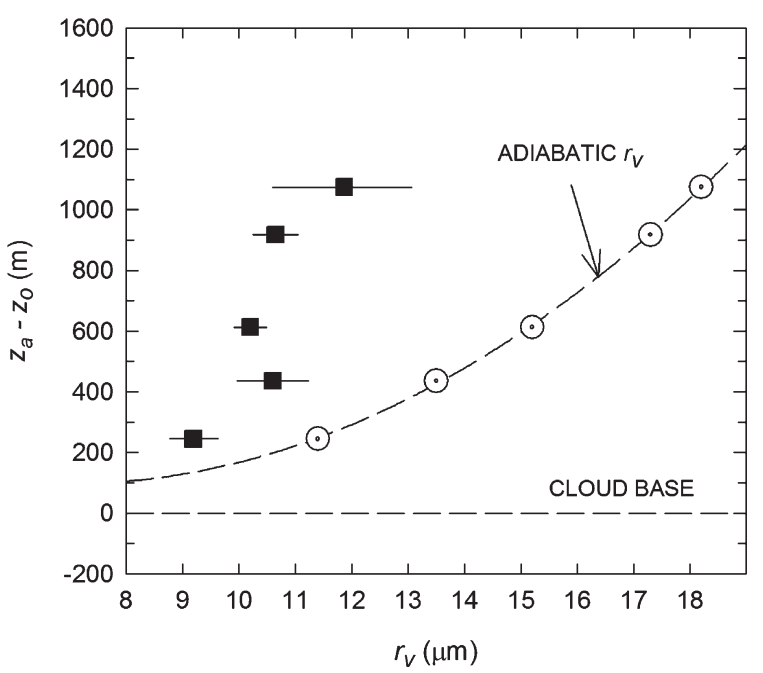

Fig. 3. Average measured values of mean volume radius $r_{v}$ for the 7 conditionallysampled $\mathrm{Cu}$ at each of 5 levels flown by the aircraft (solid squares); horizontal lines through the data indicate 2 standard deviations of data variability (similar horizontal lines in subsequent plots have the same meaning). Dashed line is the expected value of $r_{v}$ given adiabatic ascent in the $\mathrm{Cu}$.

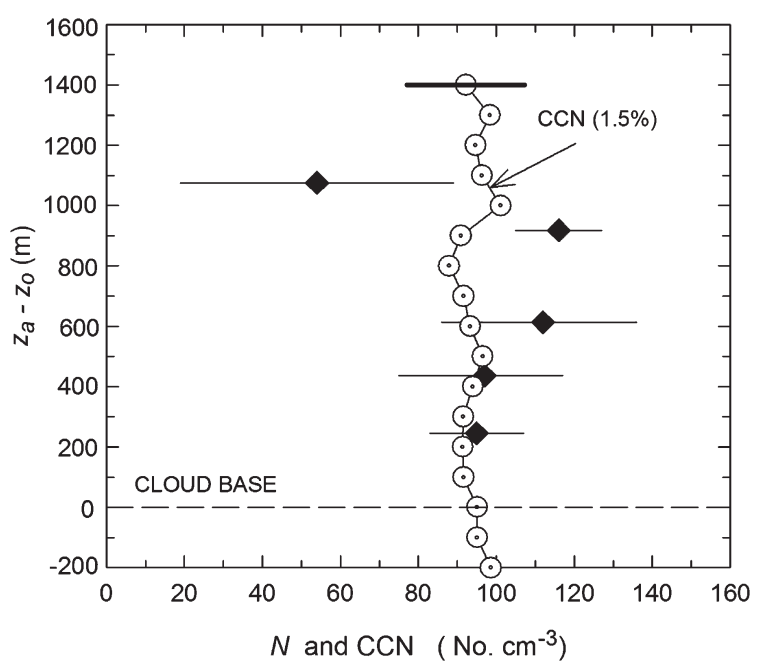

Fig. 4. Average number concentration $N$ of cloud droplets (solid diamonds) for the 7 conditionally- sampled $\mathrm{Cu}$ at 5 levels above $\mathrm{Cu}$ base. Hollow circles indicate $\mathrm{CCN}$ (cloud condensation nuclei) for a critical supersaturation of $1.5 \%$ measured during vertical profiling of the aircraft outside of cloud. (The heavy horizontal line gives the average 2 std. dev. for the $\mathrm{CCN}$ data).
Table 4. Mean value of pressure $P$, potential temperature $\theta$, virtual potential temperature $\theta_{v}$, and vapor mixing ratio $q_{v}$ for the $\mathrm{Cu}$ in Fig. 2. Subscripts $c$ and $e$ correspond to cloud and environment respectively.

\begin{tabular}{llrrrrr}
\hline \multirow{2}{*}{ Parameter } & \multicolumn{5}{c}{ Level } \\
\cline { 3 - 7 } & & \multicolumn{1}{c}{1} & \multicolumn{1}{c}{2} & \multicolumn{1}{c}{3} & \multicolumn{1}{c}{4} \\
\hline$P$ & $(\mathrm{mb})$ & 923.3 & 902.9 & 885.4 & 854.3 & 838.4 \\
$\theta_{c}$ & $(\mathrm{~K})$ & 298.8 & 299.2 & 300.5 & 301.8 & 301.6 \\
$\mathrm{~s}\left[\theta_{c}\right]$ & $(\mathrm{K})$ & .33 & .59 & .47 & .32 & .31 \\
$\theta_{v c}$ & $(\mathrm{~K})$ & 301.4 & 301.6 & 302.9 & 304.0 & 303.6 \\
$\mathrm{~s}\left(\theta_{v c}\right)$ & $(\mathrm{K})$ & .36 & .66 & .53 & .36 & .34 \\
$\theta_{e}$ & $(\mathrm{~K})$ & 299.3 & 300.2 & 300.5 & 301.8 & 302.8 \\
$\mathrm{~s}\left[\theta_{e}\right]$ & $(\mathrm{K})$ & .38 & .24 & .29 & .32 & .18 \\
$\theta_{v e}$ & $(\mathrm{~K})$ & 301.6 & 302.3 & 302.5 & 303.7 & 304.5 \\
$\mathrm{~s}\left(\theta_{v e}\right)$ & $(\mathrm{K})$ & .38 & .21 & .24 & .31 & .13 \\
$\Delta \theta_{v}$ & $(\mathrm{~K})$ & -.24 & -.70 & .36 & .25 & -.87 \\
$\mathrm{~s}\left(\Delta \theta_{v}\right)$ & $(\mathrm{K})$ & .40 & .74 & .55 & .56 & .28 \\
$q_{v c}$ & $(\mathrm{~g} / \mathrm{Kg})$ & 14.8 & 13.8 & 13.8 & 12.7 & 11.5 \\
$\mathrm{~s}\left[q_{v c}\right]$ & $(\mathrm{g} / \mathrm{Kg})$ & .31 & .52 & .41 & .26 & .22 \\
$q_{v e}$ & $(\mathrm{~g} / \mathrm{Kg})$ & 12.9 & 11.7 & 11.0 & 10.5 & 9.1 \\
$\mathrm{~s}\left[q_{v e}\right]$ & $(\mathrm{g} / \mathrm{Kg})$ & .62 & .67 & .57 & .32 & .48 \\
\hline & & & & & & \\
\hline
\end{tabular}

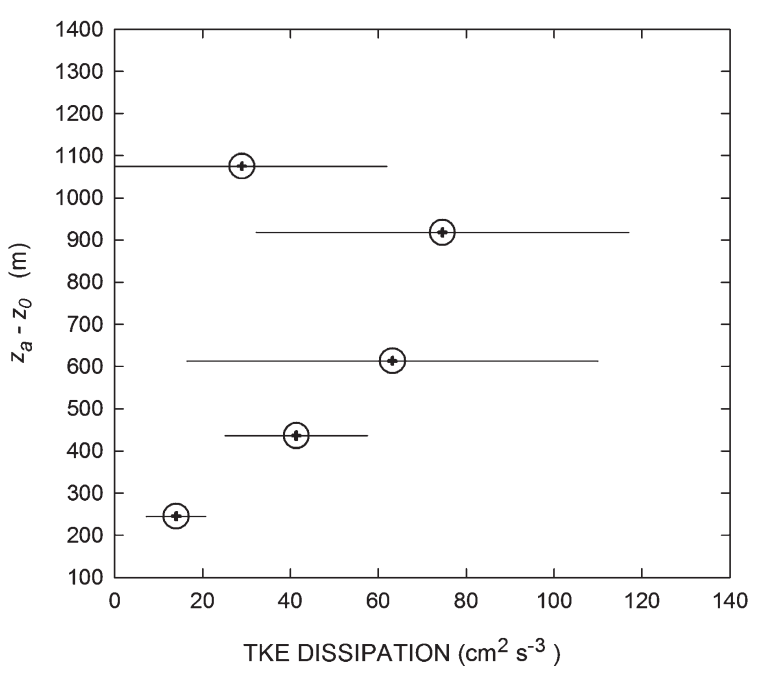

Fig. 5. Average TKE (turbulent kinetic energy) dissipation rate $(\varepsilon)$ for the conditionally-sampled $\mathrm{Cu}$ as a function of height above cloud base. 


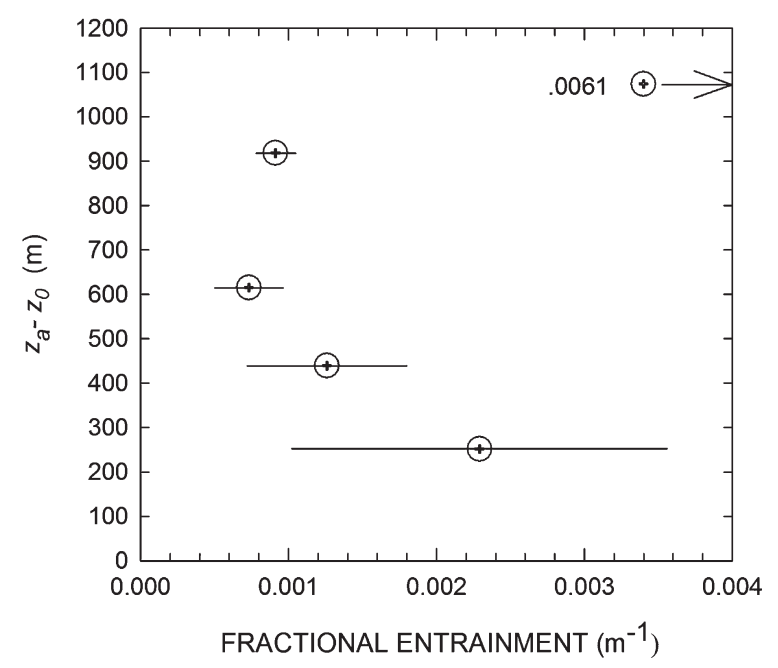

Fig. 6. Average fractional entrainment $(\delta)$ for the conditionally-sampled $\mathrm{Cu}$ as a function of height above cloud base.

ment $\delta$ calculated with

$$
\delta=\frac{\phi_{c}-\phi_{e}}{\delta \phi_{c} / \delta z}
$$

where the scalar $\phi$ is given by the total water mixing ratio $q_{T}$, the five mean values of the local vertical gradient of $\phi$ are found at the five $\mathrm{Cu}$ levels by interpolating $q_{T}$ (measured with the Lyman-Alpha and the PVM probes) between levels and extrapolating beyond the bottom and top levels, and the subscripts $c$ and $e$ represent incloud and out of cloud values respectively. The percentage of air from cloud base reaching cloud top can be roughly estimated from this $\delta$ data to be $\sim 20 \%$. The average of $\delta$ for the lower four levels is $1.30 \mathrm{~km}^{-1}$; the top level is excluded, because these $\mathrm{Cu}$ appeared to be dissipating on the average. This value of $\delta$ is identical to the average value of $\delta$ obtained by Raga et al. (1990) during JHWRP, even though their sampling of aircraft $\mathrm{Cu}$ traverses differed from the sampling used here. Modeling values for small non-precipitating $\mathrm{Cu}$ include $\delta \sim 2 \mathrm{~km}^{-1}$ (Siebesma and Cuijpers, 1995) and $\delta=1.5 \mathrm{~km}^{-1}$ (Kreuger et al. 1997).

\section{Mixing}

The mixing of entrained air with cloudy air is thought to significantly affect the droplet size spectra, although agreement on how the spectra are affected is still lacking. Three mixing mechanisms have been considered (Jensen et al. 1985): Mixing causes some of the droplets to totally evaporate while others remain unaffected termed extreme inhomogeneous mixing, the entrained air causes some droplets to evaporate more than others termed inhomogeneous mixing, and all drops are exposed to the same subsaturated conditions termed homogeneous mixing. Efforts to understand the mixing process include laboratory work of Latham and Reed (1977) who demonstrated the presence of extreme inhomogeneous mixing, and Baker et al. (1980) who applied this result to clouds. Experimental evidence supporting this mixing type is described in Paluch (1986), Blyth and Latham (1991), and Gerber (2000). However, Jensen et al. (1985) suggest the presence of homogeneous mixing in CCOPE $\mathrm{Cu}$, and Burnet and Brenguier (2007) in SCMS Cu. Modeling efforts include Jensen and Baker (1989), Su et al. (1989), and Lasher-Trapp et al. (2005), with the latter showing that the choice of the mixing mechanism strongly affects the droplet spectra found at the top of $\mathrm{Cu}$.

The present attempt to understand the mixing process uses a PVM probe which measures directly LWC and PSA (particle surface area) given by

$$
L W C\left(\mathrm{gm}^{-3}\right)=\frac{4}{3} \pi \rho_{w} \sum_{i} N_{i} r_{i}^{3},
$$

and

$$
P S A\left(\mathrm{~cm}^{2} \mathrm{~m}^{-3}\right)=4 \pi \sum_{i} N_{i} r_{i}^{2},
$$

for which the ratio of the summations provides the droplet effective radius

$$
r_{e}(\mu \mathrm{m})=\frac{30000 L W C}{\rho_{w} P S A} .
$$

$L W C, r_{e}$, and $N$ are related by

$$
L W C \approx \frac{4}{3} \pi \rho_{w} N r_{e}^{3},
$$

where $r_{e} \sim r_{v}$ (Martin et al. 1994; Gerber 1996),

$$
r_{v}=\left(\frac{\sum_{i} N_{i} r_{i}^{3}}{N}\right)^{1 / 3},
$$


and

$$
L W C=\frac{4}{3} \pi \rho N r_{v}^{3}
$$

There are two ways to look at the high rate PVM data. The first way is to relate LWC and $r_{e}{ }^{3}$ as shown in Eq. (7). Figure 7 (upper part) gives a plot of this data for one of the $\mathrm{Cu}$ (\#21) of the conditionally sampled set, with the ordinate dependent on the ratio of $r_{e}^{3} / r_{e}^{3}$ (max), where $r_{e}$ (max) is the average $r_{e}$ value near the maximum LWC measured for this $\mathrm{Cu}$. The slanted lines are calculated from the FSSP spectrum measured near the center of the $\mathrm{Cu}$ and from the exposure of all the droplets in the spectrum to entrained air covering a range of sub-saturated water-vapor values including a reduced value that evaporates all of the droplets. The numerical LWC dilution fractions give the volume of entvained air divided by a given volume of the cloud and entrained-air mixture. Under the condition that the dilution fraction $=0$ the relationship between $r_{v}$ and LWC is linear with a slope $N$ (Eq. 9) and is shown as the slanted dashed line. The slanted line with circles is also for a dilution fraction $=0$, but now represents the relationship between LWC and for $r_{e}$ (Eq. 7). The difference between the slanted $r_{v}$ and $r_{e}$ slanted lines illustrates the difference between these size parameters which becomes substantial for broader droplet size spectra. The PVM data falling on the $r_{e}$ line can only be a result of a changing $N$ if behavior is dictated by Eq. (7), which could be caused by all droplets evaporating totally or new droplets being activated without entrainment taking place. The former is unlikely given the criteria used for conditional sampling of the $\mathrm{Cu}$. These lines are labeled as the homogenous (mixing) limit. The other solid slanted lines are spectrum calculations given finite values of the LWC dilution fraction. Data falling near the horizontal dashed line would represent extreme inhomogeneous mixing if they reflect the initial LWC dilution as well as total evaporation of some of the droplets. Data falling below this line and following the slanted lines would reflect homogeneous mixing events.

The PVM data in the top of Fig. 7 is noisy, but centered mostly about the horizontal dashed line. This pattern is typical of most of the 35 conditionally-sampled $\mathrm{Cu}$ for each of which a similar plot was made. This relative constancy of $r_{e}$ for individual cloud traverses was already shown by Blyth and

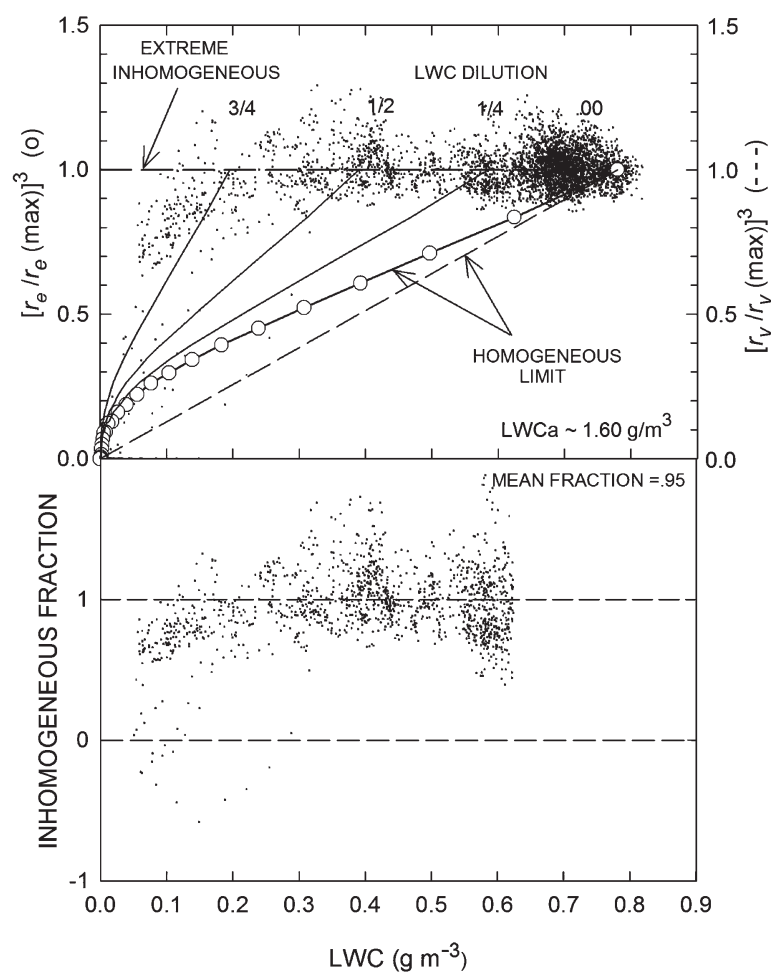

Fig. 7. Relative values of the droplets' effective radius $r_{e}$ as a function of LWC for $10-\mathrm{cm}$ incloud-resolution PVM data for the aircraft pass through one $\mathrm{Cu}$ (\#21). Slanted dashed line (upper part of Fig.) gives LWC as a function of $r_{v}$; the slanted solid lines relate LWC and $r_{e}$ for homogeneous mixing given various dilution fractions, with the line with open circles corresponding to zero dilution and named the homogeneous limit; and the horizontal dashed line represents extreme inhomogeneous mixing. The lower part gives LWC vs the inhomogeneous fraction given by using in the upper part the relative separation of the data points between the extreme inhomogeneous dashed line and the solid homogeneous limit line (see text). The estimated value for adiabatic $\mathrm{LWC}_{\mathrm{a}}$ for this $\mathrm{Cu}$ is shown.

Latham (1990) using lower resolution $\mathrm{Cu}$ data. Also typical of the plots is the deviation of $r_{e}$ from the horizontal dashed line for the smallest values of LWC. This resembles a similar but unexplained feature in the "droplet conserving wedge" for CCOPE $\mathrm{Cu}$ discussed by Jensen et al. (1985).

The lower part of Fig. 7 gives the numerical 


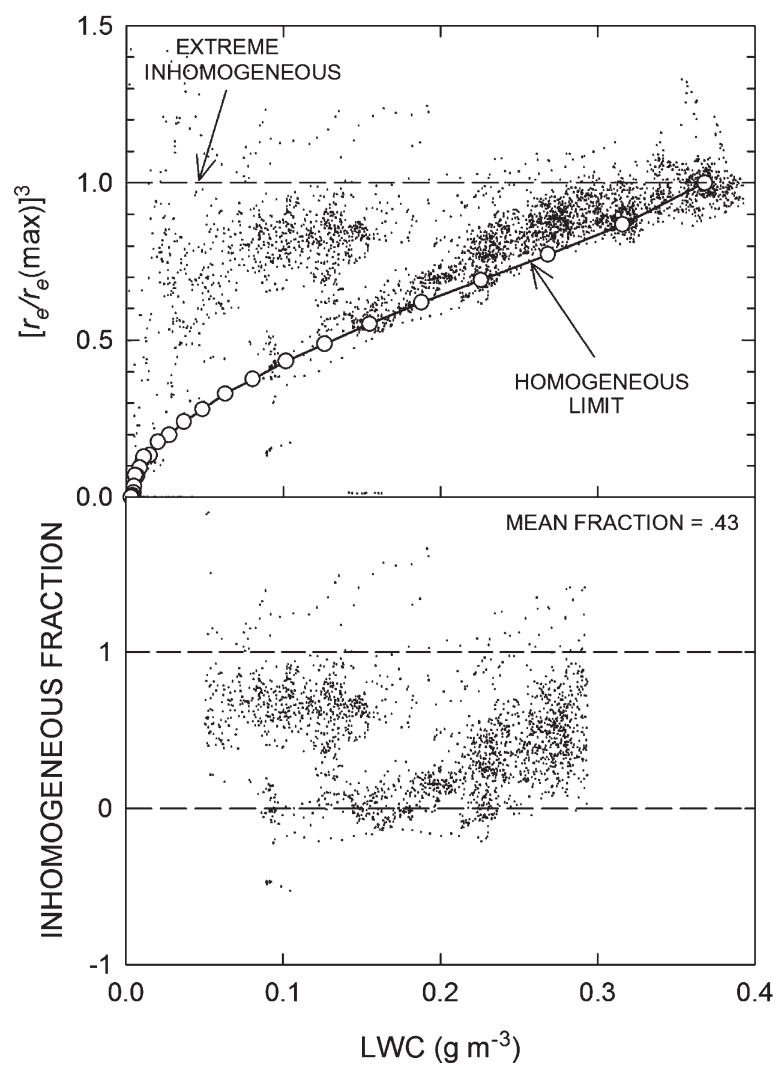

Fig. 8. Same as Fig. 7, but for an aircraft pass through another $\mathrm{Cu}(\# 6)$.

value for the average inhomogeneous fraction which is obtained by averaging the relative position of each data point in the top part between the extreme inhomogeneous horizontal line and the homogeneous limit line for $r_{e}$. The relative position is determined by dividing the vertical distance of the data point above the latter line by the vertical distance between both lines for that data point. The inhomogeneous fraction was calculated for each of the $35 \mathrm{Cu}$ to get an indication of their overall behavior in this regard.

Some of the $35 \mathrm{Cu}$ traverses, especially those closer to cloud base, did not follow the typical pattern shown in Fig. 7. Figure 8 gives an example $(\mathrm{Cu}$ \#6) which differs markedly. Here a fraction of the data points are close to the homogeneous limit curve calculated for this $\mathrm{Cu}$, suggesting that new droplets are being activated. Other data points about halfway between the horizontal and slanted lines could represent homogeneous mixing, or could be a result of this cloud containing parcels with different histories and/or with multiple mix-

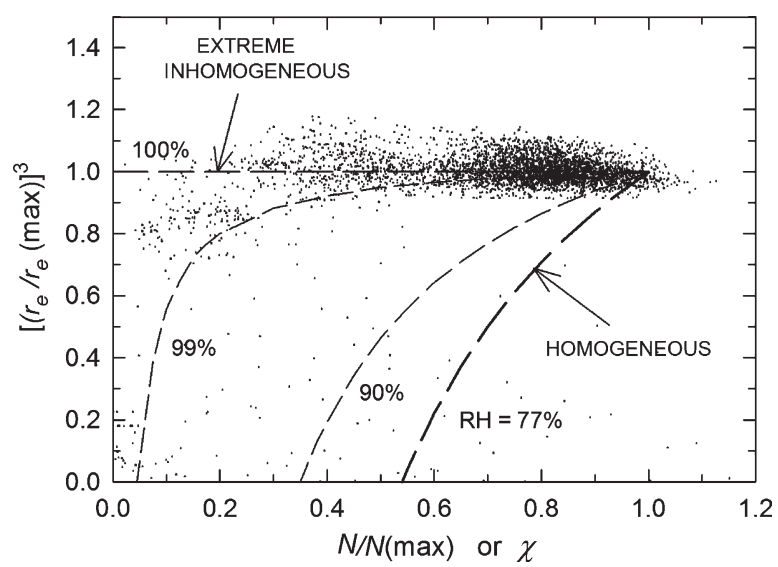

Fig. 9. Relative values of $r_{e}$ as a function of the dilution ratio $N / N_{\max }$ for the high resolution PVM data from the same cloud pass (\#21) described in Fig. 7. Curved dashed lines represent homogeneous mixing given the assumed relative humidity $(\mathrm{RH}=90 \%, 99 \%$, and $100 \%)$ in the parcel of entrained air; the thick line represents $\mathrm{RH}=77 \%$ measured in ambient air away from the cloud.

ing events (see Krueger et al. 2006; Gerber 2006).

The second way to look at the high rate PVM data is illustrated in Fig. 9, again for $\mathrm{Cu} \# 21$. Here, the value of $N$ is calculated from Eq. (7) given the measured values of LWC and $r_{e}$ (Gerber et al. 2001). This approach using $r_{v}$ instead of $r_{e}$ was used originally for SCMS $\mathrm{Cu}$ by Brenguier and Burnet (1996), and by Burnet and Brenguier (2007) using lower resolution data and normalizations to adiabatic conditions thought to exist in the SCMS Cu. Figure 9 again illustrates that the PVM $r_{e}$ data is approximately constant over a wide range of $N . \mathrm{Cu}$ \#6 was also re-plotted in this fashion (not shown). Many of the data points in this re-plot fall below the horizontal dashed line which appears to be consistent with the homogeneous mixing, as has been suggested previously. However, that is unlikely, because most of the data below the dashed line in the re-plot is related to the activation of new drops as suggested by Fig. 8 .

Burnet and Brenguier (2007) calculated the effect on $r_{v}$ and $N$ for homogeneous mixing events between cloudy air and entrained environmental air with specified relative humidity $(\mathrm{RH})$ and with a range of dilution fractions. Here the same is done for $r_{e}$ and $N$ by calculating $q_{l}, \theta_{l}$, and $T$ of the final 
mixture following entrainment. The appropriate equations are

$$
\begin{aligned}
& q_{l}=\chi\left[q_{v s c}\left(T_{c}\right)+q_{l c}\right]+(1-\chi) q_{v e}-q_{v s}(T), \\
& \theta_{l} \approx T-\frac{L_{c}}{c_{p}} q_{l}=\chi\left(T_{c}-\frac{L_{c}}{c_{p}} q_{l c}\right)+(1-\chi) T_{e}, \\
& q_{v s}(\mathrm{~g} / \mathrm{kg}) \approx \frac{3800}{P}\left[5500\left(\frac{1}{273}\right)-\frac{1}{T}\right],
\end{aligned}
$$

where Eq. (12) is the Clausius-Clapeyron equation, and where $\chi=N / N(\max )$ is the fraction of $N$ diluted by entrainment. Subscripts $c$ represent cloud, $e$ environment, $l$ liquid-water, $v$ vapor, and $s$ saturation-vapor parameters. $T=$ temperature, $P$ $=$ pressure, $L_{\mathrm{c}}=$ heat of condensation, $q=$ mixing ratio, and $c_{p}=$ heat capacity.

The preceding equations are solved for $q_{l}$ for many values of $\chi$ after choosing environmental values of $q_{v e}$ and $T_{e}$ that determine RH. LWC is calculated from $q_{l}$ and then Eq. (7) is used to calculate $r_{e}$. Figure 9 shows the resulting dashed curves for three hypothetical ambient values of $\mathrm{RH}$, with the thick curve representing the environmental $\mathrm{RH}$ measured a substantial distance away from the $\mathrm{Cu}$. It is apparent that entrainment of environmental air with increasing humidity and the resulting homogeneous mixing will cause $r_{e}$ values to approach the horizontal extreme inhomogeneous mixing line. At $\mathrm{RH}=100 \%$ the values coincide with this line as pointed out in the work of Burnet and Brenguier (2007). Thus the data in Fig. 9 for $\mathrm{Cu} \# 21$, as well as in other $\mathrm{Cu}$ with similar behavior, can represent either homogeneous mixing with entrained air at high values of RH or extreme inhomogeneous mixing. The inability on the C-130 to accurately measure $T_{e}$ close to the cloud surface makes it impossible to estimate accurately the $\mathrm{RH}$ of the air about to be entrained. The entrainment in $\mathrm{Cu} \# 21$ causes mostly only a dilution of the droplet concentration regardless of the mixing mechanism.

Figure 10 summarizes the preceding mixing analysis for the $35 \mathrm{Cu}$. The mean inhomogeneous fraction (see Figs. 7 and 8) for the $7 \mathrm{Cu}$ at each lev$\mathrm{el}$ is shown. When this fraction equals unity it must be labeled in addition as homogeneous high-RH mixing. The tendency of the data shows a sharp increase in the fraction with height with a maximum near cloud base. This should be compared with the fractional entrainment in Fig. 6 which has the same trend with height (except for the top-most

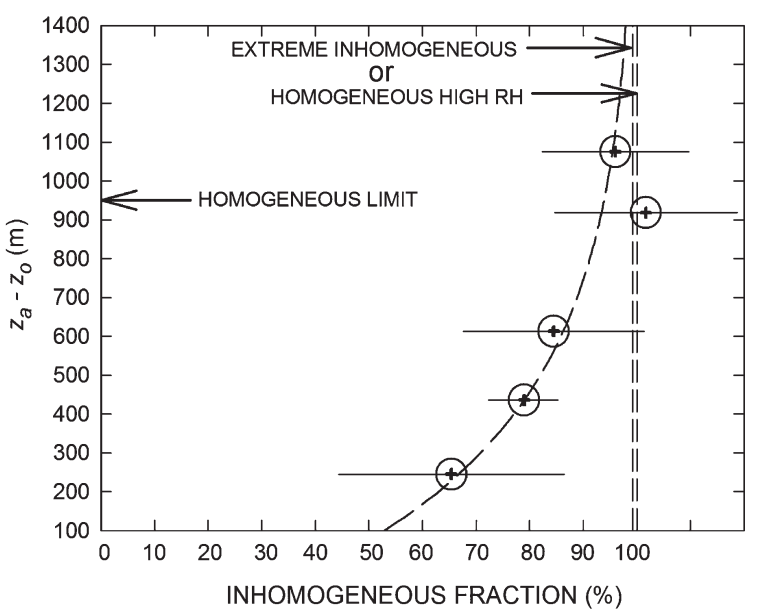

Fig. 10. Average values of the inhomogeneous fraction for the 7 conditionallysampled $\mathrm{Cu}$ at 5 levels above cloud base. The curved line is an approximate fit to the data given by $x=100-60\left(0.005^{\mathrm{y} / 2000}\right)$.

data point where on the average the $\mathrm{Cu}$ are in the process of dissipating). These tendencies suggest that the activation of new droplets in the entrained air is maximum near cloud base and decreases with height. Recent LES (large-eddy simulation) shows a similar vertical trend for the concentration of aerosol particles entrained laterally into small $\mathrm{Cu}$ (Heus et al. 2007a).

\section{Scales of entrained parcels}

Not much is known about the scales of parcels entering small $\mathrm{Cu}$ in the entrainment process. Modeling has suggested that scales a substantial fraction of the dimensions of the cloud may be involved (Grabowski and Clark 1993; Krueger et al. 1997). However, Brenguier (1993) measured with the Fast FSSP sharp gradients at cloud edge with scales as small as several $\mathrm{cm}$, and even smaller scales are suggested by Baker (1992). Similar cloud-edge geometry for LWC is noted for the 35 $\mathrm{Cu}$ and is illustrated in Fig. 11 for the C-130 aircraft penetration into the edge of one of the $\mathrm{Cu}$. Assumptions are made that rapid changes in the high-rate LWC data over a small distance interval (over an average of 3 PVM data points which is equivalent to $\sim 30 \mathrm{~cm}$ horizontal distance) and that reductions in LWC greater than the statistical sampling noise of LWC, as in the left portion of the data in Fig. 11 , indicate the presence of entrained parcels. The sampling noise is a result of the random distribu- 


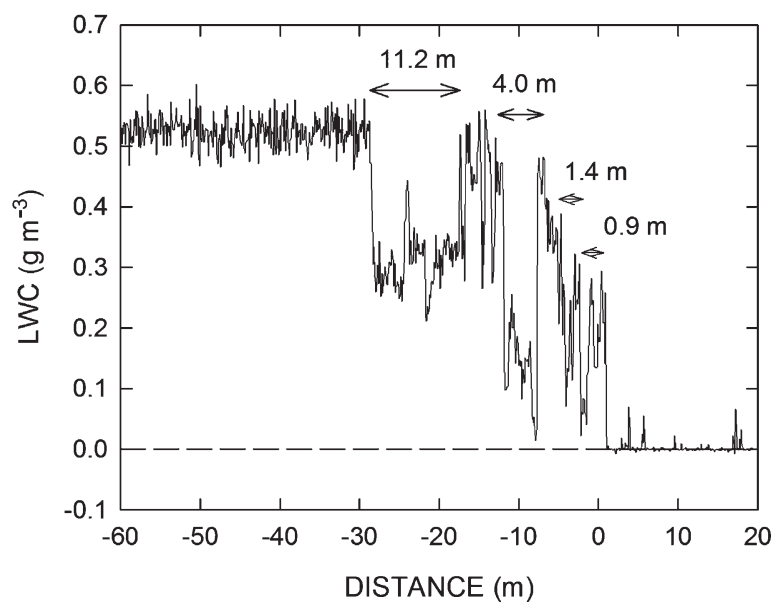

Fig. 11. High-resolution LWC measured as a function of the horizontal distance from the edge of a $\mathrm{Cu}$. Depleted LWC with sharp gradients over the indicated lengths are assumed to represent entrained parcels.

tion of cloud droplets in the cloud resulting in a variable number of droplets in the limited sample volume of the PVM. The lengths shown in Fig. 11 give the distances over which the sharply depleted LWC exist, distances named entrained parcel lengths. These lengths do not necessarily represent the scales of cloud-free parcels that initially enter the cloud during entrainment, because of the time dependence of the mixing process that can fragment and distort the initially entrained parcels. The lengths, as defined here, were picked out from C-130 passes through both cloud edges of the $28 \mathrm{Cu}$ in the lower four levels, and are shown in the distributions in Fig. 12. The probability of the lengths is distributed approximately lognormally with geometric standard deviation of $2.6 \mathrm{~m}$ and geometric mean length of $1.6 \mathrm{~m}$. The lognormal behavior suggests that if the volume of the entrained air is proportional to the entrained parcel length cubed then this volume will also be lognormally distributed with the same geometric standard deviation, but with a somewhat larger volume median diameter.

The identification of the entrained parcel lengths also leads to the observation of their penetration depth with respect to cloud edge. The distributions of these depths for the $28 \mathrm{Cu}$ are shown in Fig. 13. Here again the probability shows lognormal behavior with a geometric standard deviation of $2.9 \mathrm{~m}$
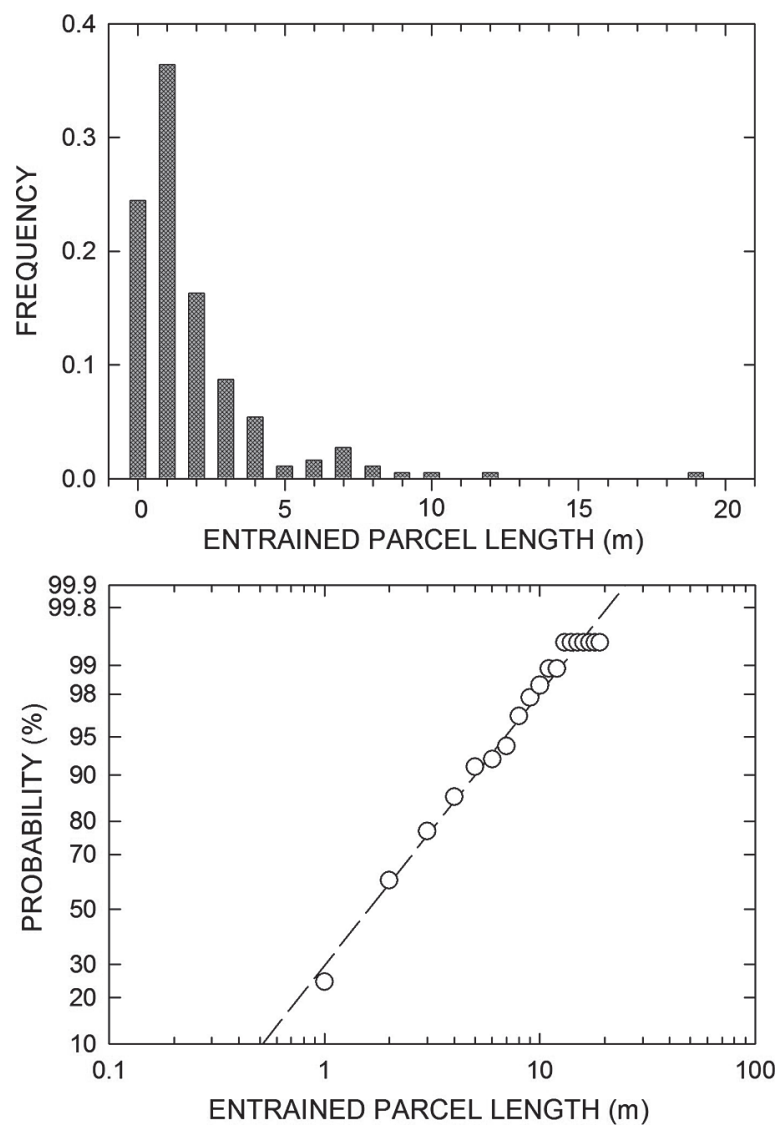

Fig. 12. Frequency distributions of entrained parcel lengths observed at cloud edges for all $\mathrm{Cu}$ at the lower 4 levels. The linear behavior in the cumulative probability plot (lower plot) indicates lognormal behavior of the lengths.

and geometric mean depth of $8.9 \mathrm{~m}$.

The dimensions of the entrained parcel lengths are unexpectedly small. Given that the entrainment observations deal only with levels of the $\mathrm{Cu}$ near cloudtop raises the possibility that the observations are also influenced by un-observed larger scales occurring lower in the $\mathrm{Cu}$. This possibility can be countered by the high-resolution PVM data from the aircraft traverses through the $\mathrm{Cu}$ showing essentially no cloud-free voids except near cloud edges, and only showing small depleted LWC parcels with rounded edges further in the $\mathrm{Cu}$. These observations can be related to the time scale given by $\tau_{\text {mix }}=\left(D^{2} / \varepsilon\right)^{1 / 3}$ (Baker et al. 1984) for complete homogenization of entrained parcels with the rest of the cloud. For example, given a parcel dimen- 

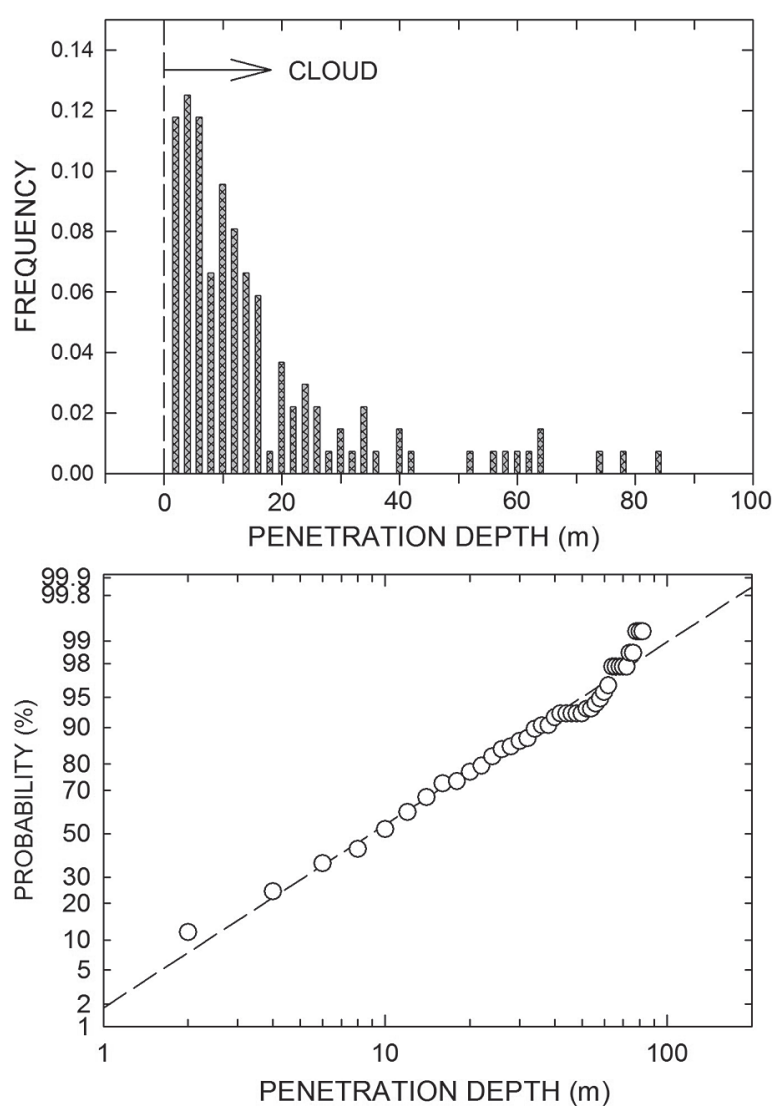

Fig. 13. Frequency distributions of the penetration depths into the $\mathrm{Cu}$ of the entrained parcels described in Fig. 12. Lognormal behavior is shown.

sion of $\mathrm{D}=2 \mathrm{~m}$, and using a mean value of $\varepsilon$ from Fig. 5, leads to a $\tau_{\text {mix }}$ of $\sim 10 \mathrm{~s}$ which is short compared to the times associated with larger-scale motions of the $\mathrm{Cu}$. Additional support for the scales and penetration depths of the entrained parcels found for the $28 \mathrm{Cu}$ comes from the similar nature of radar observations (Knight and Miller 1998) in small $\mathrm{Cu}$ of Bragg-scattering "mantle echoes". The incloud echoes often cover the region near the cloud surface, are thought to be a result of refractive index variations from fluctuations in LWC and water vapor, and are caused by scales “....that are small compared to the radar resolution (which is about $150 \mathrm{~m}$ ) but much larger than several $\mathrm{cm}$....”.

The relatively short lifetimes of the entrained parcels also reflect their point of origin. Given that aircraft traverses for the five levels average about 250-m below cloud top suggests that their origin could not have been at cloud top given the substan- tial time needed to travel that distance in subsiding cloudy air, but that their origin is instead from lateral entrainment near the height of cloud- edge penetrations. The sharp LWC gradients near cloud edge lead to the same conclusion. Also, recent LES modeling results (Heus et al. 2008a) find the same behavior where entrainment is found laterally rather than only on the top of the $\mathrm{Cu}$. The short parcel lifetimes further suggest that the entrained parcels mix with the rest of the cloud more rapidly than the time required for the droplet sizes to adjust to the new saturation environment of the mixture, causing homogeneous mixing. The droplet adjustment time is given by $\tau_{\text {drop }}=4 r^{2} /\left[4 \times 10^{-4}(1\right.$ $-S_{a}$ ) ] (Baker et al. 1984) where $S_{a}$ is water- vapor saturation $\left(S_{a}=1.00\right.$ at $\left.\mathrm{RH}=100 \%\right)$ of the mixture and where $r$ is droplet radius in $\mathrm{cm}$. Under conditions where the entrained air is sub-saturated but of high $\mathrm{RH}, \tau_{\text {drop }}$ becomes large further enhancing the possibility of homogeneous mixing. Subsiding moist and cooled air has been observed to form a shell around small $\mathrm{Cu}$ (Rodts et al. 2003; Hues and Jonker 2008b) with temperature measured at relatively low spatial resolution cooler on the order of $0.5 \mathrm{C}$ than the cloud- free ambient temperature. If this cooled air has in addition a higher $\mathrm{RH}$ than the ambient $\mathrm{RH}$ the mixing would favor homogenous mixing. Higher resolution and accurate temperature measurements are needed right at the cloud boundary to more accurately determine $\mathrm{RH}$.

The tendency of $\varepsilon$ to increase with height in the $\mathrm{Cu}$ as shown in Fig. 5 indicates that $\tau_{\text {mix }}$ will decrease upward and should also cause mixing to become more homogeneous upward. Figure 10 shows the opposite where the inhomogeneous tendency increases upward. This contradiction further suggests that the deviation from the $100 \%$ vertical line for the extreme inhomogeneous mixing in Fig. 10 depends on the entrainment and activation of new $\mathrm{CCN}$.

\section{Droplet spectra}

The evolution of the droplet-size spectra shown in Fig. 14 is estimated from the measurements and from a simple parcel model including droplet coalescence and covering the $\sim 1100$-m maximum aircraft level of the conditionally-sampled $\mathrm{Cu}$. Figure 14 shows averages of the droplet size distributions measured in the $\mathrm{Cu}$ at each of the 5 levels. Each average is made up of $1 \mathrm{hz}$ ( 100-m incloud distance) FSSP and 2D-C data measured near the center of each traverse on each level. The FSSP data shows 


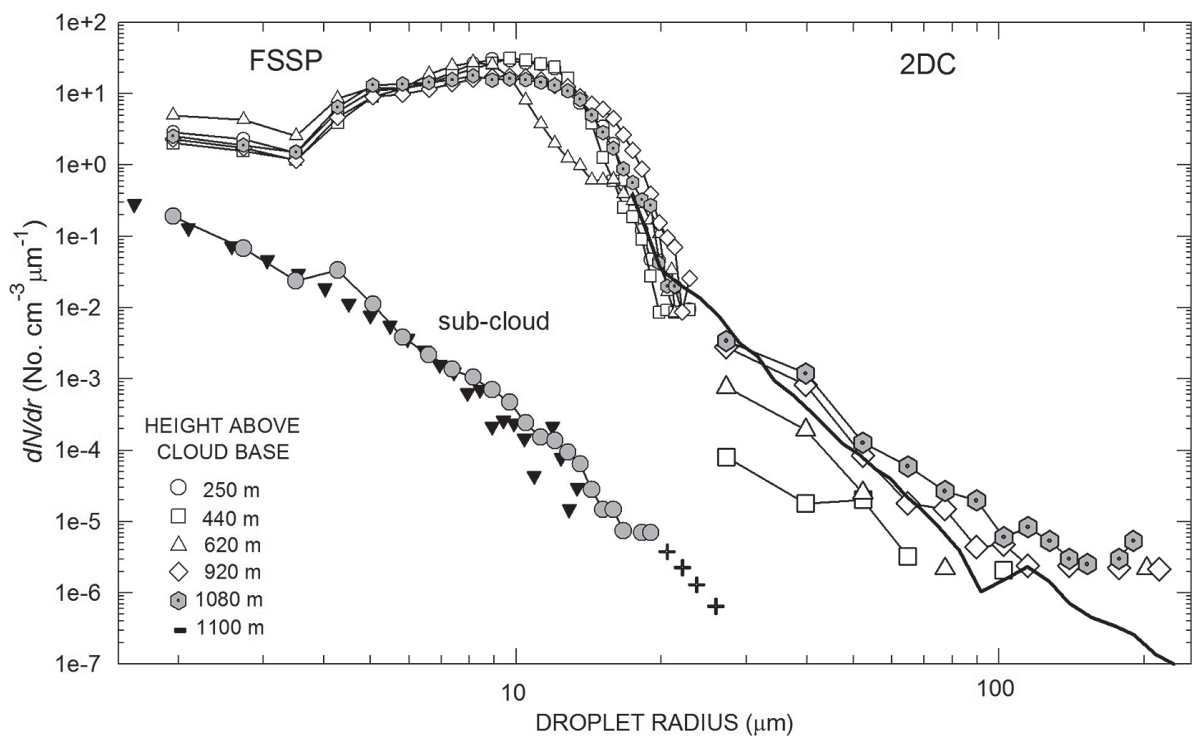

Fig. 14. Average droplet size distributions $d N / d r$ for the $7 \mathrm{Cu}$ at each of 5 levels measured incloud by the FSSP (small symbols) and by the 2D-C probe (large symbols). Subcloud distributions measured by the FSSP (gray circles) and by the GNI (solid triangles). Crosses are extrapolations of FSSP subcloud data, and the solid heavy line is the distribution predicted by the parcel model (see text).

approximately self-preserving spectra for which the size distributions hardly change with height above cloud base. The only significant deviation is seen for a portion of the spectrum for $620-\mathrm{m}$ above cloud base. On the other hand, the 2D-C spectral data show a systematic but noisy evolution of drizzle spectra to larger drops with height above cloud base.

Also shown in Fig. 14 are subcloud spectra measured by the FSSP and GNI (Giant Nuclei Impactor; see the Acknowledgments) about 100-m below cloud base. The FSSP data are the average spectra measured on two $1 / 2 \mathrm{hr} \mathrm{C}-130$ circles flown at this subcloud level about 470-m above the sea surface. The average $\mathrm{RH}$ at that level was $86 \%$, and mean wind speed was $10.6 \mathrm{~m} \mathrm{~s}^{-1}$. The GNI data in Fig. 14 is the RH-adjusted average size distribution of the particles' dry radius $\left(r_{d}\right.$; preliminary data) determined from salt-solution droplets impacted on a oilcoated slides exposed for a short time interval to the airstream on each of the $1 / 2 \mathrm{hr}$ legs. The $\mathrm{RH}$ adjustment to the equilibrium droplet radius $r$ at $\mathrm{RH}=86 \%$ is made using the haze equation (Gerber 1991)

$$
r=\left[\frac{C 1 r_{d}^{C 2}}{C 3 r_{d}^{C 4}-\log (S+1)}+r_{d}^{3}\right]^{1 / 3},
$$

where $S=-.14$ (supersaturation; $S=S_{a}-1.0$ ), $C 1=$ $0.7674, C 2=3.079, C 3=2.572 \mathrm{e}-11, C 4=-1.424$ for sea-salt particles. Reasonable agreement is seen between the two subcloud spectra.

The subcloud FSSP data can also be compared to the GNI $r_{d}$ data by applying the droplet growth equation in the form

$$
S_{e}=\frac{A}{r}-\frac{B r_{d}^{3}}{r^{3}}
$$

to the FSSP data with droplet radii assumed to be at equilibrium at the supersaturation $S_{e}=-0.14, A$ $\sim 1.13 \mathrm{e}-7 \mathrm{~cm}, B=1.02(\mathrm{NaCl})$, and solving for $r_{d}$. The comparison of $r_{d}$ values is given in Fig. 15 along with Woodcock's (1953) curves showing cumulative number of sea-salt particles vs $r_{d}$ for different Beaufort wind speeds. His curves are for particle measurements from altitudes between 600 $\mathrm{m}-800 \mathrm{~m}$, and wind-speed measurements were made at $10-\mathrm{m}$ above the sea surface. The NOAA research vessel Seward Johnson was in the vicinity off C-130 flight RF12 and measured a mean wind speed of $9.6 \mathrm{~m} \mathrm{~s}^{-1} 14-\mathrm{m}$ above the sea surface. Thus the comparison between the current $r_{d}$ values and Woodcock's curves appears supportable. The FSSP and GNI $r_{d}$ data in Fig. 15 differ by about $40 \%$, with 


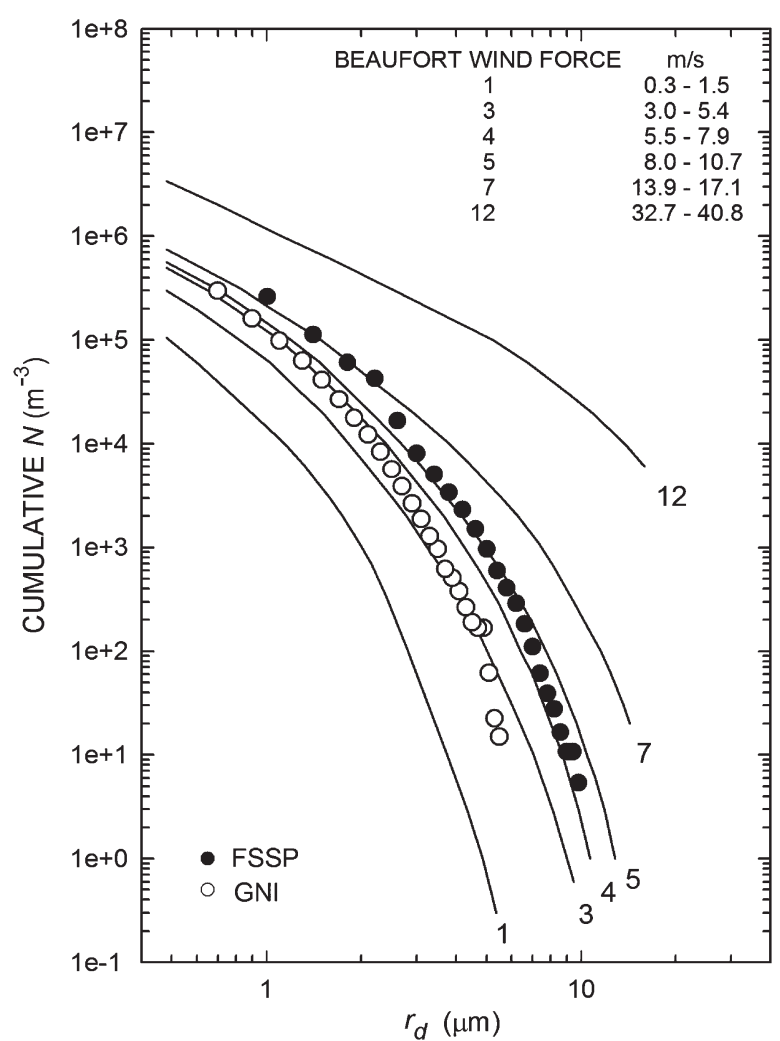

Fig. 15. Cumulative number $N$ of nuclei calculated from the Fig. 14 subcloud FSSP distribution (solid circles), and measured by the GNI (empty circles) as a function of dry nucleus radius $r_{d}$ in comparison with Woodcock's (1953) measurements of the dependence of seasalt nuclei concentrations and $r_{d}$ on the Beaufort wind force (curved lines).

the FSSP data closer to Woodcock's results. No explanation is available for this difference; however, a $\mathrm{RH}$ greater than the $86 \%$ measured at the C-130 level would bring the $r_{d}$ values closer together. The tendencies in Fig. 15 of both sets of $r_{d}$ data support the conclusion that UGN (ultra-giant nuclei are defined as particles with $r_{d}>2$ um by Beard and Ochs, 1993) are sea salt.

The parcel model is initialized with the subcloud spectrum and with the average incloud FSSP spectrum which remains unchanged. The total height of $1100 \mathrm{~m}$ of the modeling domain is divided into 100 -m thick layers $(\Delta h)$, the upward vertical velocity in each layer is assigned a value of $W_{z}=1.53 \mathrm{~m}$ $\mathrm{s}^{-1}$ which is equal to the mean value of $w$ derived from Table 2, Eq. (14) is used to calculate $r_{d}$ from the subcloud FSSP spectrum again assuming seasalt solution drops at equilibrium at ambient $S=$ -.14 , and the droplet growth equation

$$
r \frac{d r}{d t}=C\left(S-\frac{A}{r}+\frac{B r_{d}^{3}}{r^{3}}\right)
$$

is applied to the subcloud spectrum, where $C=$ $7.98 \mathrm{e}-7 \mathrm{~cm}^{2} \mathrm{~s}^{-1}, A=1.13 \mathrm{e}-7 \mathrm{~cm}, B=1.02$, and $S$ $=.0125$ for the lowest two layers and $S=0.0$ for all higher layers. The dilution effect and activation of new CCN due to entrainment, and loss of drops by detrainment are not considered in this model.

A quasi-stochastic collection process is used with the parcel model to estimate droplet growth by coalescence where a large drop of radius $r_{2}$ sedimenting with a velocity $w_{2}$ collides and merges with smaller drops of radius $r_{1}$ sedimenting at a slower velocity $w_{1}$ and located randomly in space. The number $N_{1}$ of $r_{1}$ drops collected by the larger drop over the time interval $t^{\prime}$ is given by

$$
N_{1}=K n\left(r_{1}\right) t^{\prime}
$$

where the collection kernel is

$$
K=\xi \pi s s_{c}\left(w_{2}-w_{1}\right)
$$

$n\left(r_{1}\right)$ is the concentration of $r_{1}$ drops,

$$
s=\left(\left|\left(x_{2}-x_{1}\right)\right|^{2}+\left|\left(y_{2}-y_{1}\right)\right|^{2}\right)^{1 / 2}
$$

is the separation between the center of the drops in Cartesian coordinates where the value for $x_{2}$ and $y_{2}$ for $r_{2}$ is fixed and the values for $x_{1}$ and $y_{1}$ for $r_{1}$ are generated with a random number generator,

$$
s_{c}=r_{1}+r_{2}
$$

is the critical separation that indicates the largest separation for which the drops can intercept each other geometrically, $s=s_{c}$ when $s / s_{c} \leq 1.0$, and

$$
t^{\prime}=\Delta h /\left(W_{z}-w_{2}\right)
$$

is the time the $r_{2}$ drop spends in each 100-m layer. The expression for $t^{\prime}$ includes a lengthening of time due to the sedimentation velocity of the $r_{2}$ drop. To avoid the value of $t^{\prime}$ becoming excessively large as $w_{2}$ approaches $W_{z}$ the expression for $t^{\prime}$ is only used for $r_{2}<80 \mathrm{um}$; for larger $r_{2} t^{\prime}=150 \mathrm{~s}$. These conditions are a rough guess; they relate 
to lengthier residence times of the drops in each layer due to the possibility of toroidal circulations near the top of $\mathrm{Cu}$ (Blyth et al. 1988; Stith 1992; Blyth 1993; Damiani et al. 2006).

The geometrical intersection of the drops does not always lead to their joining. The efficiency of droplet $r_{2}$ collecting droplet $r_{1}$ is the collection efficiency $\xi$ (Beard and Ochs 1993). Following Cooper et al. (1997) the collision efficiencies described by Klett and Davis (1973), Beard and Grover (1974), and Beard and Ochs (1984) are combined to determine $\xi$ (which does not include possible inertial effects). Here those $\xi$ values are approximated with an analytical expression

$$
\xi=a\left(1-b^{r_{2}}\right)-c
$$

under the conditions that if

$$
\begin{aligned}
& \xi<0, \quad \xi=0 ; \\
& r_{1}>35 \mu \mathrm{m}, \quad \xi=0.5 ; \\
& 5 \mu \mathrm{m} \leq r_{2} \leq 200 \mu \mathrm{m} ;
\end{aligned}
$$

and where $a, b$, and $c$ are given in Table 5 .

The calculations for the vertically-evolving droplet size spectrum are done in a bin-less manner (Gerber 1991) to avoid numerical broadening of the spectrum. After the final calculation the spectrum is converted back to the familiar differential form. The initial spectra are the FSSP subcloud spectrum with 32 salt-solution droplet radii ranging in size from $1.7 \mu \mathrm{m}$ to $24.4 \mu \mathrm{m}$ with size and concentration of the largest droplets extrapolated as shown by the crosses in Fig. 14, and the incloud FSSP spectrum with radii ranging in size from 4.3 $\mu \mathrm{m}$ to $19.8 \mu \mathrm{m}$ remaining unchanged throughout the calculations. Each of the subcloud radii is assigned in turn as the value for $r_{2}$ for which coalescence collection calculation are done for each of the smaller $r_{1}$ radii to determine the number of these smaller drops collected by the assigned

Table 5. Range of small drops $r_{1}$ and constants of the coalescence collection efficiency Eq. (17).

\begin{tabular}{cccc}
\hline Range $r_{1}(\mu \mathrm{m})$ & $\mathrm{a}$ & $\mathrm{b}$ & $\mathrm{c}$ \\
\hline $5.0-7.0$ & .860 & .988026 & .100 \\
$7.0-9.0$ & .991 & .977016 & .250 \\
$9.0-12.5$ & 1.14 & .967300 & .400 \\
$12.5-17.5$ & 1.70 & .943426 & 1.00 \\
$17.5-25.0$ & 1.90 & .942031 & 1.25 \\
$25.0-35.0$ & 1.79 & .911553 & 1.23 \\
\hline
\end{tabular}

larger drop. The $r_{1}$ radii are subcloud radii smaller than the assigned $r_{2}$ unless the subcloud radii are smaller than $20 \mathrm{um}$, then the mean radii for the incloud FSSP spectra are used for $r_{1}$. This procedure is repeated 128 times resulting in 4096 new droplet sizes and number concentrations which are reduced back to 32 by first sorting with increasing size the radii and associated droplet concentrations and then combining adjacent droplet sizes while conserving water and dry-salt volumes and concentrations. The 32 new categories are then applied to the next higher layer and the coalescence calculations are repeated. This approach has a minimal effect on preventing stochastic coalescence growth of a few favored drops to large sizes.

As noted, condensational growth with $S=0.0125$ is applied only to the two lowest layers while $S=0.0$ is used for all higher layers. The former value of $S$ grows the smallest subcloud salt-solution drops to match the approximately constant incloud FSSP spectrum as shown in Fig. 14, and the latter value of $S$ has only a small influence on the final calculated 2D-C spectrum, because the salt-solution drops originally assumed to be sub-saturated by $14 \%$ grow by condensation to nearly the same diluted composition and size regardless of the value of $S$ near 0.0. These assumed values of $S$ are physically unrealistic given the updrafts in the $\mathrm{Cu}$ listed in Table 2 which should cause larger supersaturations at all levels of the $\mathrm{Cu}$. However, ignoring in this simple parcel model entrainment, detrainment, and new droplet activation leads to the choice of $S$ values that causes the match between the subcloud and incloud FSSP spectra, and provides physicallymeaningful exposure of the salt-solution droplets to saturation conditions.

The heavy solid line in Fig. 14 gives the modeled spectrum at the highest level $(1100 \mathrm{~m})$. The line shows the presence of drizzle drops, but somewhat less than the measured concentration of the largest droplet sizes at $1080 \mathrm{~m}$. The spectra do not show the presence of large precipitation-sized drops. Thus these observations and modeling do not have direct bearing on the unanswered question: Do UGN cause the onset of precipitation in small $\mathrm{Cu}$ ? In support of the role of UGN the present results can be viewed as showing only the initial stages of $\mathrm{Cu}$ growth and the coalescence process since only $\sim 12$ min elapsed for these $\mathrm{Cu}$ to grow $\sim 1100 \mathrm{~m}$ and produce some large drizzle drops $\left(\sim 20 \mathrm{~L}^{-1}\right.$ for $r=25$ $\mathrm{mm} ; \sim \mathrm{L}^{-1}$ for $r=50 \mu \mathrm{m} ; \sim 1 \mathrm{~m}^{-3}$ for $\left.r=250 \mu \mathrm{m}\right)$.

The model results in Fig. 14 illustrate that the 


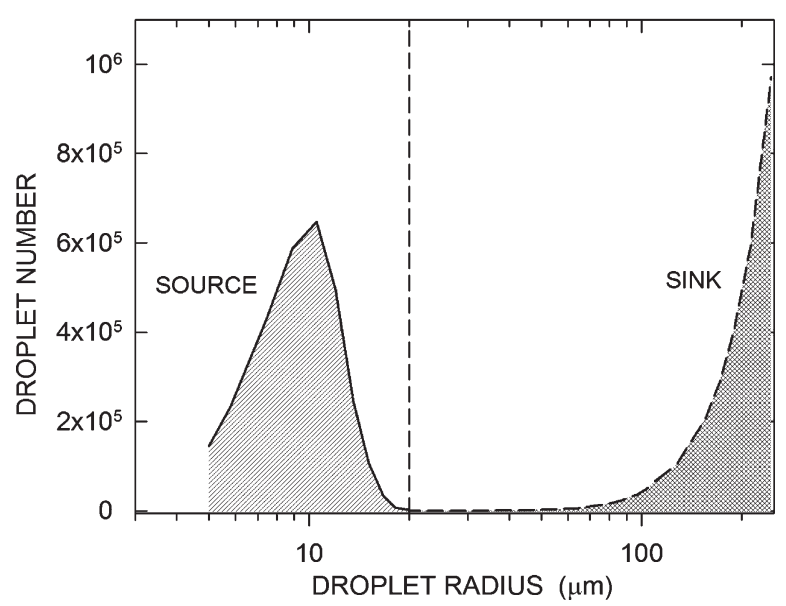

Fig. 16. Predicted number of small drops lost by coalescence (source) to larger drops (sink) as a function of drop size for the 1080-m level above cloud base (see Fig. 14). The vertical dashed line indicates the 20 - $\mu \mathrm{m}$ radius that separates the autoconversion (smaller drops) process from the accretion process

formation of the drizzle part of the spectrum is a result of the relatively rapid growth and adjustment to saturation conditions of the subcloud seasalt solution droplets that then efficiently collect by coalescence many of the large number of small droplets from the incloud FSSP spectrum. Figure 16 shows this behavior where the number of small droplets lost by collection to larger drops, and the number of droplets collected by the large drops are given as a function of droplet radius. The droplets contributing most to the coalescence LWC have $r_{1} \sim 12 \mu \mathrm{m}$. This collection process is termed accretion which is defined as the liquid-watermass transport rate across a droplet radius usually given as $20 \mu \mathrm{m}$ (Wood 2005) and shown in Fig. 16 as the vertically-dashed line. The related process is termed autoconversion where the water-mass transport rate across the $20-\mu \mathrm{m}$ radius is caused by coalescence of drops smaller than this radius, a process not evident in these trade-wind $\mathrm{Cu}$ according to the parcel model.

The total number of collections in Fig. 16 account for about $25 \%$ of the total FSSP droplet number in the vertical 1,100-m column. This in combination with the $\sim 20 \%$ survival of drops originating at cloud base leads to about an order of magnitude reduction in the FSSP concentration, which is not observed. Thus, the entrainment and activation of new CCN, as suggested by Figs. 6 and 10, must replenish the drops in the FSSP spectrum lost by detrainment and by coalescence to the drizzle part of the spectrum. Given this scenario, where a constant supply of FSSP-sized droplets feed through coalescence the larger drops formed on UGN, means that if these conditions had persisted and these $\mathrm{Cu}$ had grown taller and more mature, the growth of the drizzle spectrum would have accelerated and likely resulted in precipitation (see for comparison stochastic coalescence calculations by Berry and Reinhardt 1974, and Ochs 1978).

A few additional simulations were done to test the response of the parcel model to hypothetical changes in the cloud-droplet and subcloud saltsolution spectra. The trends found in this preliminary sensitivity study show that a decrease of the incloud droplet concentration without droplet size changes causes a significant decrease of the largest drizzle drops. If the droplet sizes are now increased to keep LWC constant then a small increase in the largest drizzle drops is found. The greatest decrease in drizzle occurs when the incloud droplet concentration is increased by a large factor, or when the UGN subcloud concentration is decreased by a large factor. Clearly, changes in small incloud droplets and UGN are closely coupled so that both must be taken into account for initiating precipitation in these small trade-wind $\mathrm{Cu}$.

A previous study (Blyth et al. 2003) of the role of UGN in small $\mathrm{Cu}$ observed during SCMS agrees with the results presented here, also suggesting the importance of UGN in initiating precipitation; although, a more recent study (Goeke et al. 2007) for the same $\mathrm{Cu}$ suggests otherwise. Three additional references (Knight et al. 2008; Colon-Robles et al. 2006; Hudson and Mishra 2007) dealing with RICO trade-wind $\mathrm{Cu}$ also deliberate the role of UGN in causing precipitation. The first reference relies again primarily on the interpretation of radar returns, while the latter two relate to measurements made from the C-130 aircraft during RICO. The second reference finds a negative correlation between near-surface wind speed and the concentration of large drops found in the cloud layer about 300-m thick adjacent to cloud base. This means that the generation of UGN which increases with wind speed results in fewer large drops which are needed for the coalescence process that leads to precipitation. In the third reference a strong nega- 
tive correlation is found between the $\mathrm{CCN}$ out-ofcloud concentration and the mean droplet diameter in the same $~ 300-m$ cloud layer, suggesting that the $\mathrm{CCN}$ rather than the much smaller concentration of UGN play the dominant role in causing precipitation. It is not possible to dismiss the inferred conclusions in these studies dealing with the role of UGN, and it is likewise not possible to accept the conclusions. Since the in-situ measurements made in the latter two studies rely on measurements made in the cloud layer just above cloud base, they only indirectly address the possibility of warm- rain formation that happens higher in the $\mathrm{Cu}$, so that the role of UGN remains unresolved. As noted by Colon-Robles et al. (2006) additional analyses and modeling studies are needed.

\section{Conclusions}

This study illustrates the degree of difficulty associated with choosing $\mathrm{Cu}$ from a complex field of $\mathrm{Cu}$ for the purpose of establishing typical microphysical behavior of the $\mathrm{Cu}$, which in this instance is the behavior of actively-growing turrets about 250-m below cloud top. Some subjectivity is needed in the conditional sampling of the $35 \mathrm{Cu}$ studied here; and the long horizontal lines in the tables and figures depicting standard deviations of the measurements lead to uncertainties in the values and trends of the cloud parameters. Further, the assumption of the Lagrangian nature of this study leads to additional uncertainty. For this assumption to be valid requires that the $\mathrm{Cu}$ sampled at various levels during RF12 remain physically consistent during the whole flight, and that a statistically significant sample of the $\mathrm{Cu}$ is chosen.

The following conclusions are given in light of the preceding caveats: The incloud comparisons during aircraft traverses of the $\mathrm{Cu}$ of the $10-\mathrm{cm}$ resolution PVM data for $\mathrm{LWC}$ and effective radius $r_{e}$ show a predominance of large changes in LWC with steady values of $r_{e}$ as also found by Blyth and Latham (1990) using similar data with 2 orders of magnitude less resolution. However, the highresolution PVM data finds instances during the traverses where this behavior is not followed which is interpreted as the influence of the activation of new droplets on entrained CCN. This effect is maximum near cloud base and decreases sharply in the upward direction which is the same tendency measured for the fractional entrainment rate.

It is not possible to clearly differentiate between the three potential mixing mechanisms (homog- enous, inhomogeneous, and extreme inhomogeneous) following entrainment of ambient air into these $\mathrm{Cu}$. However, this inability does not impact significantly on the droplets' behavior, because the predominant observed effect of entrainment on the droplet size distribution is to dilute the droplet number and not to cause the droplets to decrease in size; only when the incloud LWC is reduced to very small values is the latter generally observed, as also described previously by Jensen et al (1985). The dilution is a result of the entrainment of droplet-free air, and the effect at the small LWC values appears to be caused by homogeneous mixing with entrained air that is cool and humid and preconditioned by evaporating cloud. Although the latter could not be confirmed, because of the inability to determine accurately temperature and humidity at cloud edges, Rodts et al. (2003) and Hues and Jonker (2008b) describe the existence of a subsiding shell of cool and moist air surrounding small $\mathrm{Cu}$.

The high resolution PVM measurements also permitted identifying, sizing, and locating welldefined cloud parcels associated with the entrainment process. These parcels, identified by sharp gradients and depletions of LWC are surprisingly only on the order of meters in size and penetrate only several tens of meters into the $\mathrm{Cu}$ before being lost by mixing. This result correlates with the "mantle echo" observed in small $\mathrm{Cu}$ by Knight and Miller (1998) and identified as Bragg radar scattering from LWC and vapor inhomogeneities of about the same scale. The consequences of finding such small entrained parcels include the following: Their size suggests the scale that high-resolution dynamic models such as LES should strive to attain if the entrained parcels are to be resolved without sub-grid parameterization. Their small size also means that they rapidly mix with the rest of the cloud given incloud turbulence levels so that they do not travel far from their cloud-edge source, and that they do not cause strongly depleted LWC to survive very long incloud. The latter suggests that "super-adiabatic" drops modeled to exist under certain conditions in $\mathrm{Cu}$ (e.g., Krueger et al. 2006), are not likely to have a significant presence in these trade-wind $\mathrm{Cu}$; the high resolution $r_{e}$ measurements bear this out. The small parcels also suggest the presence of homogeneous mixing, in that the response time of droplet-size change in the cloud parcel containing entrained air appears longer than the time to totally mix the parcel with 
the rest of the cloud, especially if the entrained air is cool and humid.

The droplet-size spectra measured by the FSSP in the core (100-m average) of the $\mathrm{Cu}$ show a surprising constancy with height of the $\mathrm{Cu}$, but the 2D-C spectra show a steadily increasing "drizzletail" with height. The former self-preserving spectra are remarkable in that they apparently reflect an approximate balance between the gain of droplets by activation on entrained $\mathrm{CCN}$, loss of droplets by detrainment, loss of droplets by coalescence, and the effects on the droplet spectra from a variable mean vertical velocity and fractional entrainment with height.

The measured FSSP and UGN sub-cloud spectra agree quite well with Woodcock's (1953) classical relationships between the dry radius of sea-salt particles and the near-surface wind speed, suggesting an ample presence of ultra-giant sea-salt nuclei (UGN) on flight RF12. These spectra and the incloud FSSP spectra form the basis of a parcel model focused on the coalescence process and used to simulate the formation of the drizzle part of the observed spectra. Approximate agreement is found between the measured and simulated drizzle spectra leading to the conclusion that UGN play a significant role in forming the drizzle drops by collecting smaller drops from the FSSP self-preserving spectra. This agreement applies more to the qualitative model results rather than the quantitative results that are questionable given the applied assumptions and the simplicity of the model. It appears according to the model that accretion rather than autoconversion plays the dominant role in generating the drizzle spectra in these $\mathrm{Cu}$. It is doubtful whether parameterizations for these processes evaluated by Wood (2005) for stratocumulus clouds can be accurately applied to these tradewind $\mathrm{Cu}$; autoconversion needs some inclusion of sea-salt nuclei content for appreciable wind speeds over the ocean.

This study is far from providing final and quantitative answers on the role of UGN nuclei in the formation of precipitation in trade-wind $\mathrm{Cu}$; although, the study suggests that their role must be considered. New questions arise including the following: Is the approximate balance between coalescence losses, droplet dilution, and the activation of entrained CCN unique for flight RF12, or does a similar balance exist for other small $\mathrm{Cu}$ ? Is the present description of entrained-parcel geometry and its implications for the mixing and microphysical pro- cesses applicable to other small $\mathrm{Cu}$ ? What is the nature of the transition between the limited role thought to exist for sea-salt UGN nuclei for clean maritime air, and the role for air with sea salt but less clean maritime air such as, for example, for flight RF12? Further analyses of the unique RICO data base should help with these questions. Also, modeling with high-resolution LES and EMPM (explicit mixing parcel model; Krueger et al. 1997) is desirable for answering unresolved UGN sensitivity questions.

\section{Acknowledgments}

Thanks are due Bjorn Stevens, Robert Rauber, Harry Ochs, and Charlie Knight for organizing RICO. Appreciation is expressed to the Research Aviation Facility (RAF) of NCAR for their excellent running of RICO. Jorgen Jensen of RAF is thanked for supplying the unpublished and preliminary Giant Nuclei Impactor (GNI) data. The paper benefitted from helpful suggestions provided by Steven Krueger. The Seward Johnson data was obtained from NOAA-ESRL, Physical Sciences Div., Boulder, Co. This work was supported by NSF Grants ATM-0345695 and ATM-0342618. The National Center for Atmospheric Research is sponsored by the National Science Foundation.

\section{References}

Baker, B., 1992: Turbulent entrainment and mixing in clouds: A new observational approach. J. Atmos. Sci., 49, 387-404.

Baker, M.B., R.G. Corbin, and J. Latham, 1980: The influence of entrainment on the evolution of cloud droplet spectra: I. A model of inhomogeneous mixing. Quart. J. Roy. Meteor. Soc., 106, 581-598.

Baker, M.B., R.E. Breidenthal, T.W. Choularton, and J. Latham, 1984: The effects of turbulent mixing in clouds. J. Atmos. Sci., 41, 299-404.

Beard, K.V. and S.N. Grover, 1974: Numerical collision efficiencies for small raindrops colliding with micron size particles. J. Atmos. Sci., 31, 543-550.

Beard, K.V. and H.T. Ochs III, 1984: Collection and coalescence efficiencies for accretion. J. Geophys. Res., 89, 7165-7169.

Beard, K.V. and H.T. Ochs III, 1993: Warm-rain initiation: An overview of microphysical mechanisms. J. Appl. Meteor., 32, 608-625.

Berry, E.X. and R.L. Reinhardt, 1974: An analysis of cloud drop growth by collection: Parts I-IV. J. Atmos. Sci., 31, 1814-1831.

Blyth, A.M., 1993: Entrainment in cumulus clouds. $J$. Appl. Meteor., 32, 626-641. 
Blyth, A.M. and J. Latham, 1990: Aircraft studies of altitudinal variability in the microphysical structure of non-precipitating, ice-fee, Montana cumulus. Quart. J. Roy. Meteor. Soc., 116, 1405-1423.

Blyth, A.M., W.A. Cooper, and J.B. Jensen, 1988: A study of the source of entrained air in Montana cumuli. J. Atmos. Sci., 45, 3944-3964.

Blyth, A.M., S.G. Lasher-Trapp, W.A. Cooper, C.A. Knight, and J. Latham, 2003: The role of giant and ultragiant nuclei in the formation of early radar echoes in warm cumulus clouds. J. Atmos. Sci., 60, 2557-2572.

Brenguier, J.-L., 1993: Observations of cloud microstructure at the centimeter scale. J. Appl. Meteor, 32, 783-793.

Brenguier, J.-L. and F. Burnet, 1996: Experimental study of the effect of mixing on droplet spectra. Proc. $12^{\text {th }}$ Int. Conf. Clouds and Precip. Zurich, Switzerland, 67-70.

Burnet, F. and J.-L. Brenguier, 2007: Observational study of the entrainment-mixing process in warm convective clouds. J. Atmos. Sci., 64, 1995-2011.

Colon-Robles, M., R.M. Rauber, and J.B. Jensen, 2006: Influence of low-level wind speed on droplet spectra near cloudbase in trade wind cumulus. Geophys. Res. Lett., 33, L20814, doi:10.1029/2006 GL027487.

Cooper, W.A., R.T. Bruintjes, and G.K. Mather, 1997: Calculations pertaining to hygroscopic seeding with flares. J. Appl. Meteor., 36, 1449-1469.

Damiani, R., G. Vali, and S. Haimov, 2006: The structure of thermal in cumulus from airborne dualDoppler radar observation. J. Atmos. Sci., 63, 1432-1450.

Gerber, H., 1991: Supersaturation and droplet spectral evolution in fog. J. Atmos. Sci., 48, 2569- 2588.

Gerber, H., 1996: Microphysics of marine stratocumulus clouds with two drizzle modes. J. Atmos. Sci., 53, 1649-1662.

Gerber, H., 2000: Structure of small cumulus clouds. Proc. $13^{\text {th }}$ Int. Conf. Clouds and Precip. Reno, Nevada, 105-108.

Gerber, H., 2006: Entrainment, mixing, and microphysics in RICO cumulus. Proc. $12^{\text {th }}$ Conf. On Cloud Physics. Amer. Meteor. Soc., Madison, WI, paper 14.2A.

Gerber, H., B.G. Arends, and A.K. Ackerman, 1994: New microphysics sensor for aircraft use. Atmos. Res., 31, 235-252.

Goeke, S., H.T. Ochs, and R.M. Rauber, 2007: Radar analysis of precipitation initiation in maritime versus continental clouds near the Florida Coast: Inferences concerning the role of $\mathrm{CCN}$ and giant nuclei. J. Atmos. Sci., 64, 3695-3707.

Grabowski, W.W. and T.L. Clark, 1993: Cloud-environment interface instability. Part II: Extension to three spatial dimensions. J. Atmos. Sci., 50, 555-
573.

Hudson, J.G., 1989: An instantaneous CCN spectrometer. J. Atmos. Oceanic Technol., 6, 1055-1065.

Hudson, J.G. and S.S. Yum, 2001: Maritime-continental drizzle contrasts in small cumuli. J. Atmos. Sci., 58, 915-926.

Hudson, J.G. and S. Mishra, 2007: Relationship between $\mathrm{CCN}$ and cloud microphysics variations in clean maritime air. Geophys. Res. Lett., 34, L16804, doi:10.1029/2007GL030044.

Heus, T., G. Van Dijk, H.J.J. Jonker, and H.E.A. Van Den Akker, 2008a: Mixing in shallow cumulus clouds by Lagrangian particle tracking. J. Atmos. Sci., 65, 2581-2597.

Heus, T. and H.J.J. Jonker, 2008b: Subsiding shells around shallow cumulus clouds. J. Atmos. Sci., 65, 1003-1018.

Jensen, J.B., P.H. Austin, M.B. Baker, and A.M. Blyth, 1985: Turbulent mixing, spectral evolution and dynamics in a warm cumulus cloud. J. Atmos. Sci., 42, 173-192.

Jensen, J.B. and M.B. Baker,1989: A simple model of droplet spectral evolution during turbulent mixing. J. Atmos. Sci., 46, 2812-2829.

Klett, J.D. and M.H. Davis, 1973: Theoretical collision efficiencies of cloud droplets at small Reynolds numbers. J. Atmos. Sci., 30, 107-117.

Knight, C.A. and L.J. Miller, 1998: Early radar echoes from small, warm cumulus: Bragg and hydrometeor scattering. J. Atmos. Sci., 55, 2974-2992.

Knight, C.A., L.J. Miller, and R.A. Rilling, 2008: Aspects of precipitation development in trade wind cumulus revaled by differential reflectivity at $\mathrm{S}$ band. $J$. Atmos. Sci., 65, 2563-2580.

Krueger, S.K., C.-W. Su, and P.A. McMurty, 1997: Modeling entrainment and finescale mixing in cumulus clouds. J. Atmos. Sci., 54, 2697-2712.

Krueger, S.K., P.J. Lehr, and C.-W. Su, 2006: How entrainment and mixing scenarios affect droplet spectra in cumulus clouds. Proc. $12^{\text {th }}$ Conf. On Cloud Physics. Amer. Meteor. Soc.,Madison, WI, paper 9.2.

Lasher-Trapp, S.G., W.A. Cooper, and A.M. Blyth, 2005: Broadening of droplet size distributions from entrainment and mixing in a cumulus cloud. Quart. J. Roy. Meteor. Soc., 131, 195-220.

Latham, J. and R.L. Reed, 1977: Laboratory studies of the effects of mixing on the evolution of cloud droplet spectra. Quart. J. Roy. Meteor. Soc., 103, 297-306.

Malkus, J.S., 1949: Effects of wind shear on some aspects of convection. Trans. Amer. Geophys. Union, 30, 19-25.

Martin, G.M., D.W. Johnson, and A. Spice, 1994: The measurement and parameterization of effective radius of droplets in warm stratocumulus clouds. J. Atmos. Sci., 51, 1823-1842. 
Ochs, H.T., 1978: Moment-conserving techniques for warm cloud microphysical computations. Part II: Model testing and results. J. Atmos. Sci., 35, 1959 $-1973$.

Paluch, I.R., 1986: Mixing and the droplet size spectrum: generalizations from the CCOPE data. $J$. Atmos. Sci., 43, 1984-1993.

Raga, G.B., J.B. Jensen, and M.B. Baker, 1990: Characteristics of cumulus band clouds off the coast of Hawaii. J. Atmos. Sci., 47, 338-355.

Rauber, R.M., B. Stevens, and co authors, 2007: Rain in shallow cumulus over the ocean-The RICO campaign. Bull. Amer. Meteor. Soc., 88, 1912-1928.

Rodts, S.M.A., P.G. Duynkerke, and H.J.J. Jonker, 2003: Size distributions and dynamical properties of shallow cumulus clouds from aircraft observations and satellite data. J. Atmos. Sci., 60, 18951912.

Scorer, R.S. and F.H. Ludlam, 1953: Bubble theory of penetrative convection. Quart. J. Roy. Meteor. Soc., 79, 94-103.

Siebesma, A.P. and J.M.W. Cuijpers, 1995: Evaluation of parametric assumptions for shallow cumulus convection. J. Atmos. Sci., 52, 650-666.

Squires, P., 1958: The microstructure and colloidal sta- bility of warm clouds. Tellus, 10, 256-261.

Stevens, B. and A. Seifert, 2007: On the sensitivity of simulations of shallow cumulus convection to their microphysical representation. J. Meteorol. Soc. Japan, (submitted).

Stith, J.L.,1992: Observations of cloud-top entrainment in cumuli. J. Atmos. Sci., 49, 1334-1347.

Stommel, H., 1947: Entrainment of air into a cumulus cloud. J. Meteor., 4, 91-94.

Su, C.-W., S.K. Krueger, P.A. McMurty, and P.A. Austin,1998: Linear eddy modeling of droplet spectral evolution during entrainment and mixing in cumulus clouds. Atmos. Res., 47-48, 41-58.

Tennekes, H. and A.G.M. Driedonks, 1981: Basic entrainment equations for the atmospheric boundary layer. Boundary Layer Meteorol., 20, 515-531.

Warner, J., 1955: The water content of cumuliform cloud. Tellus, 7, 449-457.

Wood, R., 2005: Drizzle in stratiform boundary layer clouds. Part II: Microphysical aspects. J. Atmos. Sci., 62, 3034-3050.

Woodcock, A.H., 1953: Salt nuclei in marine air as a function of altitude and wind force. J. Meteor., 10, 362-371. 